\title{
Exposure effects on music preference and recognition
}

\author{
ISABELLE PERETZ and DANIELLE GAUDREAU \\ University of Montreal, Montreal, Quebec, Canada \\ and \\ ANNE-MARIE BONNEL \\ Center of Cognitive Neuroscience, CNRS, Marseille, France
}

\begin{abstract}
In three experiments, the effects of exposure to melodies on their subsequent liking and recognition were explored. In each experiment, the subjects first listened to a set of familiar and unfamiliar melodies in a study phase. In the subsequent test phase, the melodies were repeated, along with a set of distractors matched in familiarity. Half the subjects were required to rate their liking of each melody, and half had to identify the melodies they had heard earlier in the study phase. Repetition of the studied melodies was found to increase liking of the unfamiliar melodies in the affect task and to be best for detection of familiar melodies in the recognition task (Experiments 1,2, and 3). These memory effects were found to fade at different time delays between study and test in the affect and recognition tasks, with the latter leading to the most persistent effects (Experiment 2). Both study-to-test changes in melody timbre and manipulation of study tasks had a marked impact on recognition and little influence on liking judgments (Experiment 3). Thus, all manipulated variables were found to dissociate the memory effects in the two tasks. The results are consistent with the view that memory effects in the affect and recognition tasks pertain to the implicit and explicit forms of memory, respectively. Part of the results are, however, at variance with the literature on implicit and explicit memory in the auditory domain. Attribution of these differences to the use of musical material is discussed.
\end{abstract}

As music listeners, we are conservative: We like the music that we already know. This knowledge does not need to be extensive. Often, a single prior exposure with a particular musical selection will induce a positive reaction toward it. This phenomenon has been known for a long time by social psychologists (see Meyer, 1903, for the pioneering study). It may also account for the effectiveness of advertising jingles, as it may explain the appeal of some highly repetitive music. However, the mechanisms that underlie this memory-biased attitude toward music remain largely unknown. The goal of the present set of studies was to explore one possible theoretical framework for the mere exposure effect on liking judgments by relating it to the current conceptualization of implicit memory.

This research was supported by a research grant to the first author and a fellowship to the second author from the Natural Sciences and Engineering Research Council of Canada (NSERC) and by a summer studentship from the Fonds de la Recherche en Santé du Québec (FRSQ) to Véronique Reich. We are grateful to Véronique Reich, Gaëtane Chapelle, Sylvie Noël, and Bernard Bouchard for their help with the material and subject testing. We also thank John Seamon, Michael Masson, and an anonymous reviewer for their comments on an earlier draft. Correspondence should be addressed to 1 . Peretz, Département de Psychologie, Université de Montréal, C.P. 6128, succ. Centre-ville, Montréal, PQ, H3C 3J7 Canada (e-mail: peretzi@magellan.umontreal.ca).

-Accepted by previous associate editor Michael E. J. Masson

\section{The Mere Exposure Effect for Music}

Most people have experienced a mere exposure effect at one time or another. Some may even report how they came to like a given musical genre that they had disliked initially. Often, this occurs through passive exposure to samples of a novel musical genre by an enthusiast imposing this new music on them. This positive effect of prior exposure on music liking - which we will refer to as the mere exposure effect - is not limited to private experience. It can also be demonstrated in a laboratory setting.

The first to document this phenomenon was Meyer (1903), who presented to subjects a dozen repetitions of a piece of Oriental-like music (containing quarter-tone intervals instead of the semitone intervals to which Western listeners are accustomed) that he had composed. After the last repetition, most subjects declared "that the aesthetic effect is improved by hearing the music repeatedly" (p. 474). This frequency-affect relation has been confirmed in many subsequent studies (Gilliland \& Moore, 1924; Heingartner \& Hall, 1974; Johnson, Kim, \& Risse, 1985; Krugman, 1943; Lieberman \& Walters, 1968; Moore, 1914; Mull, 1957; Verveer, Barry, \& Bousfield, 1933; Washburn, Child, \& Abel, 1927; Wilson, 1979; but see Brickman, Redfield, Harrison, \& Crandall, 1972, and Heyduk, 1975, for negative results) for a large variety of music. Mere exposure effects on affect judgments have been obtained with classical music (both tonal and atonal: see, e.g., Gilliland \& Moore, 1924; Mull, 1957), jazz (see, 
e.g., Verveer et al., 1933), Korean (Johnson et al., 1985), and Pakistani (Heingartner \& Hall, 1974) music, as well as random tone sequences (Wilson, 1979). It is worth noting that all these studies used very few excerpts (on average, 4.6, ranging from 1 to 9 stimuli). The fact that a large majority of these studies nevertheless obtained evidence for a frequency-affect relation suggests that the mere exposure effect is a pervasive phenomenon in music.

Despite its robustness, there has not been much study on the effect of repetition on liking in recent years. Thus, little is known about the conditions and parameters that enhance or reduce the exposure-affect relation. Of most relevance to the present study is the observation that the connection between stimulus repetition and likability was typically disclosed to the subjects in these past studies (with the notable exception of Johnson et al.'s (1985) study, to which we will return shortly). That is, the subjects were aware that frequency of exposure was the experimental variable at study. Awareness of such a relation may influence performance in unpredictable directions. Some subjects may view repetition as tiresome, whereas others may view it as instructive, consequently engaging in cognitive activities that can be quite remote from the mere effects of repetition. However, the observation of a rather systematic positive bias in preference suggests that cognitive evaluation of the task does not play an important role.

This has been more recently confirmed by Johnson et al. (1985), who showed that prior exposure can positively bias affect for music, with little or no conscious awareness. In that study, both neurologically intact subjects and Korsakoff amnesic patients were presented with Korean musical excerpts that were repeated a variable number of times $(1,5$, or 10 times $)$ in a study phase. The subjects were required to judge whether the stimuli sounded Chinese or American; they were not informed about the connection between this study phase and the following tests of affect and recognition judgments (performed in that order a few days apart). In the affect test, the subjects were presented with the studied melodies mixed with unstudied ones and were required to rate their liking of each stimulus on 5-point scale (1 meaning dislike most, and 5 meaning like most). Both amnesic and neurologically intact subjects exhibited a robust effect of repetition on liking judgments-that is, they rated the studied melodies higher than the nonstudied ones. This preference emerged after a single prior presentation and did not reliably increase with repetition number. In the recognition test, the same subjects were required to judge which melody out of each pair (formed by one studied and one nonstudied melody) sounded familiar and to rate their level of confidence in their decision on a 3-point scale. On recognition judgments, amnesic patients were (by definition) impaired, as compared with normal controls; thus, they demonstrated memory-biased performance in liking with little recognition. On the other hand, for normal subjects, an increased number of repetitions improved recognition, while having little impact on af- fect judgments, thereby further strengthening the dissociation between the memory mechanisms that govern liking judgments and those that subserve recognition.

Such dissociation between affect and recognition is not specific to music. It has been recurrently observednotably, in the visual domain - that stimuli that cannot be recognized can still be distinguished on the basis of affective ratings (see Bornstein, 1989, for a review). Zajonc (1968), who reviewed much of the early evidence and who introduced the term mere exposure effect to refer to this phenomenon, considered it to arise from the operation of a precognitive emotional system that is distinct from the memory system. However, this interpretation was later questioned, notably by Mandler, Nakamura, and Van Zandt (1987), who demonstrated that the mere exposure effect is not restricted to emotional evaluation. In their study, which involved brief exposures to random polygons, subjects selected unrecognized targets when asked to choose the brightest of a target-distractor pair, whereas another group chose the same targets when asked to select the darkest stimulus. Thus, repeated, unreinforced exposure to a stimulus can lead to a more positive evaluation of brightness in both directions. This finding has led a number of researchers (e.g., Bornstein \& d'Agostino, 1994; Jacoby \& Kelley, 1987; Seamon, Brody, \& Kauff, 1983) to view the mere exposure effect as resulting from an increase in perceptual fluency due to repetition. By this account, repeated exposure to a stimulus facilitates subsequent perceptual processing of the stimulus, and subjects attribute this facilitation to liking the stimulus or to any other nonemotional judgment (e.g., the brightness judgment). As we will argue next, these perceptual fluency effects, or the mere exposure effects, fit with the current conceptualization of implicit memory.

\section{The Mere Exposure Effect as an Implicit Memory Phenomenon}

In our view (along with many others, including Greve \& Bauer, 1990; Schacter, 1987; Seamon et al., 1995; Squire, 1992; Tobias, Kihlstrom, \& Schacter, 1992), the mere exposure effect is best conceptualized as an implicit memory phenomenon. First, the mere exposure effect fits with the definition of implicit memory, as is clarified below. Second, viewing the mere exposure effect in terms of implicit memory provides a theoretical framework that is presently lacking. Third, studying the mere exposure effect as pertaining to the class of implicit memory phenomena allows us to exploit research strategies that have proven to be effective in uncovering the nature of the underlying mechanisms. Therefore, relating the mere exposure effect to implicit memory research is worthwhile from both a theoretical and an empirical point of view.

Implicit memory refers to the behavioral changes that are attributable to a prior episode with an item and that cannot be accounted for by explicit memory for that event. Typically, implicit memory is revealed by tasks that do not require intentional or conscious recollection 
of events (Schacter, 1987). For example, in their pioneering study, Warrington and Weiskrantz (1970) presented a list of words to be studied to amnesic patients and their normal controls. Later, they asked the subjects to complete a series of nonstudied and studied word stems with the first word that came to mind. Both amnesic patients and control subjects exhibited a bias to complete the stems with the studied words. When required to intentionally recall the studied words as completions for the same stems, not surprisingly, amnesic patients performed poorly. Thus, both amnesic and normal subjects showed facilitation in stem completion that was attributable to a prior experience. Nevertheless, amnesic patients were unable to remember the experience itself. This situation illustrates the dissociation between implicit and explicit memory (for a review, see Moscovitch, Vriezen, \& Goshen-Gottstein, 1993). It should be apparent that this type of dissociation is very close to that observed by Johnson et al. (1985) on music with affect and recognition tasks.

The dissociation between implicit and explicit memory is not limited to amnesic patients, where explicit memory is impaired and implicit memory is spared. Similar dissociations can be experimentally induced in the performance of normal subjects. The research strategy consists of selecting variables that differentially affect performance on explicit and implicit memory tasks. For example, levels of processing (LOP) of the studied items affect performance on subsequent explicit tests but not on implicit ones; in contrast, changes in modality between study and test affect most forms of implicit memory tasks but not explicit memory ones (see Roediger \& McDermott, 1993, for a review). In keeping with the word stem completion task originally developed by Warrington and Weiskrantz (1970), it has been shown that having subjects judge the pleasantness of words or the clarity of pronunciation has no effect on the subsequent (implicit) completion of the stems of these words. In contrast, pleasantness judgments improve explicit recall of the presented word, when cued with its initial segment (see, e.g., Schacter \& Church, 1992). These findings suggest that stem completion depends on a processing system that does not represent the meaning of a word, whereas explicit cued recall does involve such representation. In contrast, stem completion is sensitive to the perceptual form of the studied word. Changes in the structural aspects of the words between the study phase and the stem completion phase, such as those produced by a change in modality of presentation (i.e., from auditory presentation of the word to visual presentation of the stem), reduce the magnitude of the implicit memory effects but not of the explicit ones (see, e.g., Bassili, Smith, \& MacLeod, 1989; Carlesimo, Marfia, Loasses, \& Caltagirone, 1994; Craik, Moscovitch, \& McDowd, 1994; Marsolek, Kosslyn, \& Squire, 1992; Rajaram \& Roediger, 1993).

Although studies of implicit memory most commonly have been done with words, in principle a large variety of tasks and materials can reveal the impact of prior ex- perience on subsequent judgments or actions. It can be demonstrated in movement reproduction (see, e.g., Van der Linden, Lories, \& Cornille, 1993) and in object decision tasks on line drawings (see, e.g., Schacter, Cooper, \& Delaney, 1990; Schacter, Cooper, Delaney, Peterson, \& Tharan, 1991). Likability or affect judgments, as used in the mere exposure paradigm, represent one more class of judgments that can reveal the operations of implicit memory mechanisms. This account has been recently supported in the visual domain (Seamon et al., 1995). Seamon and his collaborators based the design of their study of the mere exposure effect on the studies, conducted by Schacter and his collaborators, of implicit and explicit memory for possible and impossible visual objects. They presented line drawings in a study phase and then required subjects to perform a forced-choice affect task ("Which stimulus do you like best ?") or a recognition task ("Which stimulus did you see before?") on target-distractor pairs. The reasoning behind the research was that, if the mere exposure effect on liking demonstrates implicit memory, it should be influenced by experimental variables in the same manner as in Schacter et al.'s work. The outcome was largely consistent with those of Schacter et al. Notably, number of stimulus exposures had no effect on implicit memory in either the affect task or the object decision test, and subjects demonstrated stochastic independence between implicit and explicit memory judgments in both experimental situations. The implicit nature of the affect task was further demonstrated in Seamon et al.'s (1995) study by showing that subjects exposed to line drawings for $4 \mathrm{msec}$ showed significant preference for targets over distractors in the absence of recognition. Overall, the results support the notion that performance on the affect task is governed by implicit memory, whereas performance on the recognition task demonstrates explicit memory.

These conclusions may generalize to the case of music, although this is not warranted. For one thing, the visual and auditory modality of presentation are fundamentally different. In general, implicit memory effects are much better understood in the visual than in the auditory domain, simply because of the more extensive study of the former. Thus, most theoretical accounts of implicit memory phenomena are based on data from visual tasks and typically entail hypotheses about the characteristics of visually based processes and systems. In recent years, however, an increase in research activities on auditory events, mainly conducted by Schacter and Church (e.g., Church \& Schacter, 1994; Schacter \& Church, 1992, 1995), has led to the formulation of more general proposals that incorporate auditory mechanisms. Yet, these auditory mechanisms deal with word identification, not music. So far, musical stimuli have played no part in these theoretical developments.

\section{The Present Study}

To establish the implicit nature of the mere exposure effects in the musical domain, we designed an experimental situation that would satisfy the retrieval inten- 
tionality criteria formulated by Schacter, Bowers, and Booker (1989), so as to study memory functioning in normal subjects. In the study phase, all the subjects incidentally encoded the musical material by performing a familiarity decision task (i.e., "Is this melody familiar?"). In the test phase, the subjects were presented with the same material, half of which corresponded to the melodies presented in the study phase. They all responded by rating their judgments on a 10-point scale. In the affect task, the judgment was to rate each stimulus from I do not like it to I like it a lot. In the recognition task, the subjects were required to rate their confidence in recognizing each stimulus as having been presented in the prior familiarity decision task from no, certain to yes, certain. Thus, the recognition task required subjects to intentionally retrieve the initial study episode, whereas the affect task did not. The situation satisfied the first criterion of retrieval intentionality, which requires that the external cues available to subjects be the same in the two tests, so that only test instructions differ.

The second criterion is to select an experimental variable that will serve to dissociate the two tests. Several such variables were selected, including delay between study and test, encoding tasks, study-test changes in perceptual attributes, and familiarity with the melodies. With the exception of the last factor, all the other variables have been largely exploited in past research as a means to dissociate implicit and explicit memory. The rationale for selecting familiarity with the melodies as a new dissociative treatment was its potential for yielding memory effects in opposite directions in the affect and recognition tasks, thereby resulting in a crossover interaction. We predicted that the memory effects should be maximal on affect ratings for unfamiliar melodies, whereas recognition memory would be best for familiar melodies. The reasoning was as follows. For the affect task, already highly familiar excerpts, such as the ones presented here (e.g., the tune of "Happy Birthday"), should be clearly preferred to the unfamiliar excerpts (that corresponded to rarely played or sung melodies taken from the same popular repertoire; Berthier, 1979). Yet, these familiar melodies may be so overlearned that additional exposure in the study phase may not make a difference; thus, the effect of prior exposure should emerge more clearly in liking the repeated novel melodies over the ones heard for the first time. This is, in fact, what we observed in the normal controls' data from a previous study (Peretz, 1996). These effects were, however, limited to half the material used here and thus deserve replication. The reverse trend was expected to emerge from the recognition judgments, following the recurrent observation that preexisting material is retained better than novel material, be it faces (Ellis, Shepherd, \& Davies, 1979; Klatzky \& Forrest, 1984) or melodies (Bartlett, Halpern, \& Dowling, 1995; Java, Kaminska, \& Gardiner, 1995; Peretz, 1996), when explicit recognition memory is probed. Whether this memory advantage for familiar melodies over unfamiliar ones is due to the use of preexisting representations or to recourse to more elaborative, associative encoding is not known. By both accounts, however, subjects are expected to recognize familiar melodies much better than unfamiliar ones. In sum, prior knowledge of the melodies was expected to facilitate recognition of the studied items without increasing their relative preferences, whereas the opposite effect was expected to emerge in the treatment of the unfamiliar melodies. On the latter, higher preference for the presented melodies was expected to emerge without (or with weak) recollection.

Because familiarity with melodies was the dissociative variable that had the best potential for producing a crossover interaction, it was systematically included in all experiments. In Experiment 2, we explored the longevity of the memory effects by manipulating the time delay between study and test. By analogy with visual studies, we expected that exposure effects would persist longer in the affect task than in the recognition task. In Experiment 3, the effects of study-test changes in the perceptual form of the melodies, made by manipulating their timbre, were examined, in an attempt to relate the mere exposure effect to the functioning of the perceptual processing system for music. Similarly, manipulation of LOPs at encoding in Experiment 3 was expected to influence the recognition process but not the affect evaluation.

\section{EXPERIMENT 1}

\section{Method}

Subjects. Forty-eight subjects from the University of Montreal, between 20 and 39 years of age $(m=25)$, participated in Experiment 1 . They were recruited with an advertisement to participate in an experiment on music perception. Care was taken to avoid psychology students who might already be familiar with implicit memory concepts. All were nonmusicians and raised in a French-speaking culture to ensure a shared knowledge of popular music. The subjects were paid for their participation.

Materials. The material consisted of 80 melodic lines taken from the popular repertoire (Berthier, 1979). These melodies were divided into two sets (Set A and Set B), so that each contained 20 familiar and 20 unfamiliar excerpts. The familiar melodies were equally familiar in the two sets, with a mean rating of 4.5 and 4.3 (following our normative data, where 1 means unfamiliar, and 5 highly familiar; Peretz, Babaï, Lussier, Hébert, \& Gagnon, 1995) for Sets $A$ and $B$, respectively. They were also matched in length, with an average duration of 9.1 and $8.8 \mathrm{sec}$ for Sets A and B, respectively. The unfamiliar melodies were also matched in length in the two sets, with means of 8.1 and $7.9 \mathrm{sec}$; they came from the same songbook (Berthier, 1979) and were selected because they were no longer sung or played. No normative data were available for these unfamiliar melodies. All melodies were generated by a Yamaha TXZ synthesizer controlled by an IBM-compatible computer with the timbre approximation of a piano and were recorded on two tapes. One tape contained Set A, followed by all 80 melodies (which corresponded to the melodies of Set A mixed with those of Set B, which thus served as distractors for Set $A$ ) in a random order; the other tape contained Set B, followed by the same 80 melodies but recorded in a different random order. There was a 5-sec intertrial interval between consecutive melodies throughout the tapes.

Design and Procedure. The experiment used a $2 \times 2 \times 2$ factorial design. The between-subjects variable was the type of task (affect vs. recognition), with 24 subjects in each task, and the 
Table 1

Mean $z$ Score Transforms (and Standard Deviations) of the Subjects' Ratings on a 10-Point Scale for the Affect Task as a Function of Prior Exposure and Familiarity With the Music at Test and Retest in Experiment 1

\begin{tabular}{|c|c|c|c|c|c|c|c|c|}
\hline \multirow[b]{3}{*}{ Phase } & \multicolumn{4}{|c|}{ Familiar Music } & \multicolumn{4}{|c|}{ Unfamiliar Music } \\
\hline & \multicolumn{2}{|c|}{ Presented } & \multicolumn{2}{|c|}{ Nonpresented } & \multicolumn{2}{|c|}{ Presented } & \multicolumn{2}{|c|}{ Nonpresented } \\
\hline & $M$ & $S D$ & $M$ & $S D$ & $M$ & $S D$ & $M$ & $S D$ \\
\hline Test & .22 & .36 & .24 & .27 & -.13 & .28 & -.33 & .33 \\
\hline Retest & .43 & .26 & .47 & .26 & -.39 & .23 & -.51 & .30 \\
\hline
\end{tabular}

within-subjects variables were familiarity with the melodies (familiar vs. unfamiliar) and prior exposure (presented vs. nonpresented). Two subgroups of 12 subjects each were randomly assigned to each tape in each group defined by task. The subjects were tested individually.

The prerecorded tapes were delivered at a comfortable listening level through loudspeakers located in front of the subject. All the subjects were told that they would participate in two tests involving music; they were not informed that the two tasks were connected in any way. During the first test-the study phase, which consisted of 20 familiar musical excerpts randomly mixed with 20 unfamiliar ones-the subjects were required to decide whether each excerpt was familiar to them and to mark their responses in the provided space on an answer sheet. This task requirement permitted the verification of subjects' familiarity with the stimuli and encouraged careful listening. After the study phase, there was a retention interval of approximately $5 \mathrm{~min}$, during which the instructions for the following test, which comprised 80 test trials, were given. One group of subjects was told that the second test was an inquiry about musical taste for a future study. They were required to rate their liking of each melody on a 10 -point scale, with 1 meaning I do not like it, and 10 I like it a lot. The other group of subjects was required to judge whether they had heard each musical excerpt in the prior test on a 10-point scale (with l meaning no, I certainly haven't heard this melody in the prior test, and 10 yes, I certainly have heard that melody in the prior test). The subjects were encouraged to make use of the full scale. The experimental session lasted about $45 \mathrm{~min}$.

After examining the data, we decided to explore retention of the melodies after a delay of several months. Out of the 48 subjects tested in the first session, 39 ( 19 for the affect task and 20 for the recognition task) agreed to come back to the laboratory. For each task, an equal number of subjects was tested after an interval between test and retest of 2 and 4 months. The subjects were retested in the same conditions as those at test. The relation between the first and second session was not disclosed to the subjects; they were simply told that we needed to collect more data on the same type of judgments. None of the subjects was informed that the material was in fact identical to what they had previously heard. The subjects who initially performed the affect task were simply required to perform again the same type of judgments. For the subjects who initially performed the recognition test, the instructions were more problematic; the subjects had to recall that a few months ago they had performed a familiarity decision test on melodies that they were required, once again, to recognize among distractors.

\section{Results}

In the study phase, the a priori familiarity with the musical selections was confirmed, since the subjects achieved a hit rate of .85 and .89 in the groups subsequently performing the affect and recognition tasks, respectively. The associated false alarm (FA) rates were .10 and .08 , respectively. Responses were considered as hits when they indicated familiar to a familiar melody and as FAs when they indicated familiar to an unfamiliar melody. Sets A and $B$ also yielded similar familiarity ratings, with .88 and .86 hits, respectively; the corresponding rates of FA (.13 and .05 ) did not differ from each other $[t(46)=0.745$, $S E_{\mathrm{dm}}=0.11, \mathrm{n} . \mathrm{s} . \mathrm{l}$.

In the test phase, each subject's rating on the 10-point scale was normalized, in order to control for individual differences in the use of response scales. Indeed, there was some variability: Individual means ranged between 3.9 and 6.6, and individual standard deviations between 1.4 and 3.8. Thus, each rating was converted to a $z$ score, using the subject's own mean and standard deviation. This was done by subtracting from each rating the subject's mean rating and by dividing this result by the subject's overall standard deviation. The averaged normalized ratings are used as dependent variables in all reported analyses, unless measures derived from the application of the signal detection theory are used instead.

Preliminary analyses were performed to assess whether some difference might exist between our two sets (A and B) of stimuli. Since no difference or interaction between the sets and the factors of interest could be found, the data were collapsed over the two sets in the following analyses.

The mean $z$ scores obtained in the affect task are presented in Table 1. A positive score indicates a positive rating (above the subjects' midpoint ratings, thus indicating a yes, I like it or yes, I have heard it before), and a negative score indicates a negative response (tending toward a no, I don't like it or no, I have not heard it). As can be seen in Table 1 (under the test condition), the results were generally consistent with the predictions. The subjects preferred the familiar over the unfamiliar melodies. A single prior exposure did not affect their preference for the already familiar music but did increase their liking for the unfamiliar selections. It is worth mentioning that the lack of differential liking for the familiar melodies was not due to a ceiling effect. Subjects rated, the studied and nonstudied familiar melodies, on an average, $6.6(S D, 1.09)$ and $6.5(S D, 0.80)$, respectively, on the 10-point scale. Similar values were obtained in the next two experiments, as well as in our previous study (Peretz, 1996). For the recognition task, the discriminability and criterion measures, ${ }^{1}$ derived from the signal detection theory (and presented in Figure 1), indicate that the subjects were quite accurate at recognizing the presented from the nonpresented material and appeared to do so better for the familiar than for the unfamiliar selections.

To assess these effects statistically, two separate analyses of variance (ANOVAs) were performed on the ratings: one for the affect judgments and one for the recognition judgments. Furthermore, priming was measured in the affect task by taking into account the baseline levels.

Affect task. The ANOVA, taking familiarity and presentation as within-subjects factors, revealed an interaction between these two factors $\left[F(1,23)=8.31, M S_{\mathrm{e}}=0.03\right.$, $p<.01]$, indicating that prior study increases liking of unfamiliar melodies $\left[t(23)=3.424, S E_{\mathrm{dm}}=0.04, p<\right.$ 
DISCRIMINABILITY

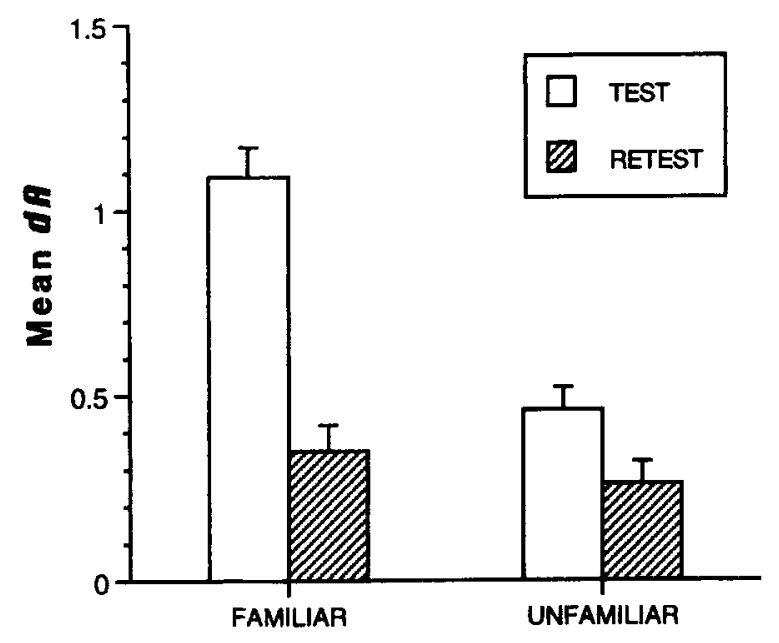

Music

\section{CRITERION}

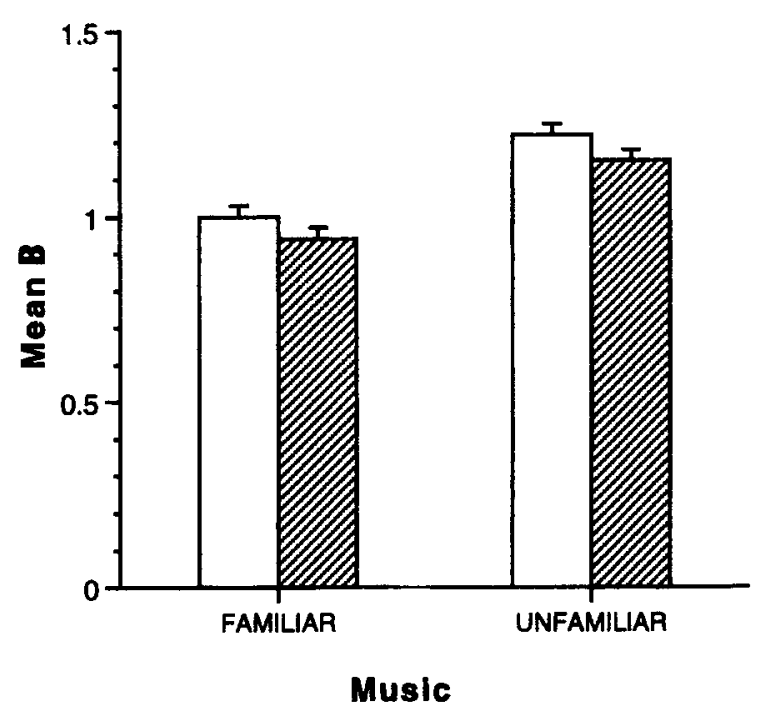

Figure 1. Discriminability (left panel) and criterion measures (right panel) for the familiar and unfamiliar musical excerpts, derived from signal detection procedures applied to the recognition ratings at test and retest in Experiment 1 . Error bars represent standard errors.

.001 , by a unilateral test] but does not influence affect ratings for familiar melodies $\left[t(23)=0.282, S E_{\mathrm{dm}}=0.04\right]$. Familiar melodies are generally preferred to the unfamiliar melodies, as supported by the presence of a main effect of familiarity $\left[F(1,23)=17.50, M S_{\mathrm{e}}=0.28, p<.001\right]$.

To ensure that the effect of prior study (i.e., repetition) was not the product of a liking bias for a subset of melodies, the mean rating obtained without prior exposure for the same stimuli (corresponding to the ratings provided by the subjects who were exposed to the other set) were subtracted from each subject's ratings obtained for the presented stimuli. We will refer to these subtracted scores as the priming scores throughout the paper. The priming scores were significantly different from zero for the unfamiliar excerpts [with a mean score of .20, $t(23)=$ $3.330, S E_{\mathrm{dm}}=0.06, p<.005$, by a one-tailed test] but not for the familiar material.

Recognition task. In order to dissociate accuracy from criterion shifts in the recognition of familiar and unfamiliar melodies, we applied the signal detection theory (Green \& Swets, 1966) to the data. The individual recognition ratings were analyzed by using standard procedures for estimating accuracy and bias parameters from receiver operating characteristic (ROC) curves. ${ }^{2}$ There were 10 response categories, from 1 (certain, new, which corresponds to the noise-alone distribution) to 10 (certain, old, which corresponds to the signal + noise distribution). The nine boundaries between adjacent pairs of these 10 categories yielded 9 points on a ROC curve, from which maximum likelihood parameter estimates were obtained with the procedure of Dorfman and Alf (1969). These iterative procedures were used for each individual subject and each material (familiar vs, unfamiliar melodies). From each ROC, accuracy was estimated by the distance measure $d_{a}$, which is equivalent to the area under the ROC.

The mean $d_{a}$ for the familiar and unfamiliar melodies are presented in Figure 1 (in the test condition). As can be seen, discriminability was much superior for familiar than for unfamiliar melodies $\left[t(23)=6.82, S E_{\mathrm{dm}}=0.07\right.$, $p<.001$, by a one-tailed test], although accuracy still was above chance level (being zero) for the unfamiliar melodies $\left[t(23)=7.712, S E_{\mathrm{dm}}=0.05, p<.001\right]$. Most remarkable is the observation that the slopes of the ROC curves are close to 1 , being 1.0 and .98 for the familiar and unfamiliar melodies, respectively, thus resembling the discrimination curves of psychophysics. Finally, the index $\beta$ was computed for each subject in order to obtain an overall assessment of bias in the choice between the responses old and new. To this end, the 10 rating categories were collapsed into 2 response categories. The $\beta$ values are presented in Figure 1. As can be seen, the $\beta$ values are close to 1 for the familiar music, indicating essentially no response bias $\left[t(23)=0.333, S E_{\mathrm{dm}}=0.03\right]$, whereas for the unfamiliar music subjects exhibit a bias toward responding new $\left[t(23)=6.736, S E_{\mathrm{dm}}=0.03, p<.001\right]$. This shift in criterion as a function of familiarity was significant $\left[t(23)=5.161, S E_{\mathrm{dm}}=0.03, p<.001\right]$.

Test-retest comparison. The data obtained on retest after an interval of several months are presented in Table 1 for the affect task and in Figure 1 for the recognition task. As can be seen, the data obtained after retesting followed essentially the same pattern as that observed at test, although being generally less positive. These retest scores were analyzed following the same separate analyses as those performed on test scores. The retest scores were then statistically compared to the test scores of those subjects 
who were tested in both sessions in a combined ANOVA, considering test-retest session as an additional withinsubjects factor in each task.

In the affect task, the retest scores gave rise to a marginal interaction between familiarity and presentation $\left[F(1,18)=3.12, M S_{\mathrm{e}}=0.03, p<.10\right]$, indicating that previously presented unfamiliar melodies were still preferred over the nonpresented ones. Although weaker, the effect of prior exposure for unfamiliar melodies reached significance on priming scores $\left[t(18)=1.782, S E_{\mathrm{dm}}=\right.$ $0.05, p<.05$, by a one-tailed test]. Thus, the mere exposure effect appears to be long lasting. Comparison of test and retest scores revealed only one significant difference, in the form of an interaction between session and familiarity $\left[F(1,18)=10.56, M S_{\mathrm{e}}=0.17, p<.005\right]$. Compared with initial testing, the subjects were found to like familiar melodies more and unfamiliar melodies less on retest.

In the recognition task, as $d_{a}$ measures indicate, the subjects no longer recognized familiar melodies better than unfamiliar melodies $\left[t(19)=1.103, S E_{\mathrm{dm}}=0.06\right]$, although they performed better than chance in both cases [with $t(19)=4.943$ and $4.210, S E_{\mathrm{dm}}=0.07$ and $0.06, p<$ .001 , for the familiar and unfamiliar music, respectively]. Statistical comparison with the test scores confirms this difference in the role of familiarity on memory recognition over time, with an interaction between session and familiarity $\left[F(1,19)=24.03, M S_{\mathrm{e}}=0.06, p<.001\right]$. The response criteria (see the right panel in Figure 1) remained essentially unchanged between test and retest. There was no effect of session $\left[F(1,19)=2.03, M S_{\mathrm{e}}=0.02\right]$ or interaction with familiarity $(F<1)$ on the $\beta$ values.

\section{Discussion}

The results replicate previous studies that showed the presence of a mere exposure effect on music liking after a single repetition (Heingartner \& Hall, 1974, Experiment 1; Johnson et al., 1985; Peretz, 1996). The present results further qualify the exposure effect in showing that it is limited to novel melodies. A single repetition was sufficient to bring about an increase in liking for novel melodies. This effect was still present at retest a few months later, hence appearing to be both reliable and long lasting. Repetition of highly familiar melodies does not increase their high level of preference, although the fact that they are generally preferred to unfamiliar melodies of the same genre indicates a preference bias for what is already known. Noteworthily, the liking judgments are not influenced in the same manner by preexisting knowledge of the music as are recognition judgments. Recognition is best for familiar melodies that are, however, not distinguishable in terms of likability. Thus, as expected, prior knowledge of melodies exerted a differential effect on affect and recognition judgments. These results support the view that the memory effects observed in affect and recognition for the same melodies have different origins, ascribed to the operations of implicit and explicit memory, respectively.
To our surprise, recognition memory was found to be both reliable and long lasting for novel melodies. Not only were the subjects able to recognize melodies after a single presentation, they also displayed enduring memories for these novel melodies; they were still able to recognize them after a delay of several months. This performance is quite puzzling, given that the so-called nonpresented novel melodies were in fact presented twice as distractors, due to the retest procedure. The problem with this procedure, however, is that it confounds time delay with task repetition. The longevity of memory effects was more properly assessed in the following experiment in which the time delay between study and test was systematically increased without repeating the test procedure.

\section{EXPERIMENT 2}

The purpose of this experiment was to reduce the strength of recognition memory so as to produce a stronger dissociation between the affect and recognition tasks. In Experiment 1, the two tasks could be dissociated in the treatment of familiar melodies that were clearly distinct in memory and not in affect. In the present experiment, we sought to extend this dissociation in the opposite direction, by showing that prior experience with novel melodies can be distinguished by affect and less so by recognition. This pattern can be expected to emerge after insertion of a long time interval between study and test. Exposure effects have been shown to persist longer in liking evaluation than in recognition judgments, at least in the visual domain (Seamon et al., 1983). In that study, time delays of $24 \mathrm{~h}$ and of 1 week were examined. Preference for previously seen stimuli did not decline over the 1-week period, whereas accuracy of recognition judgments dropped to chance level over the same delay periods. In the present situation, however, recognition of melodies was expected to decline over time to a level that would be still above chance, given the results obtained in Experiment 1, whereas preferences were expected to remain stable. The time intervals inserted between study and test were originally set to $5 \mathrm{~min}$, as in Experiment 1 , to provide a baseline against which to assess the effect of increasing time delay to 1 day ( $24 \mathrm{~h}$ ), to 1 week, and to 1 month. In each condition, two different groups of subjects studied the same sets of 40 melodies, half of which were familiar to them, and returned to the laboratory after the same delay period to perform either the affect task or the recognition task. In these two tests, half the melodies were previously studied, half were not. To test all time delays in each task, eight groups of 20 subjects each were scheduled to participate in the experiment. Two groups were dropped from the actual design when it became apparent that recognition memory did not significantly decline over a 1 -week period.

\section{Method}

Essentially the same materials and procedures as those of Experiment 1 were employed. The only differences were a slight 
Table 2

Mean $z$ Score Transforms (and Standard Deviations) of the Subjects' Ratings for the Affect Task as a Function of Familiarity With the Music After Various Delays Between Presentation and Test (Experiment 2)

\begin{tabular}{|c|c|c|c|c|c|c|c|c|}
\hline \multirow[b]{3}{*}{ Delay } & \multicolumn{4}{|c|}{ Familiar Music } & \multicolumn{4}{|c|}{ Unfamiliar Music } \\
\hline & \multicolumn{2}{|c|}{ Presented } & \multicolumn{2}{|c|}{ Nonpresented } & \multicolumn{2}{|c|}{ Presented } & \multicolumn{2}{|c|}{ Nonpresented } \\
\hline & $M$ & $\overline{S D}$ & $M$ & $S D$ & $M$ & $\overline{S D}$ & $M$ & $S D$ \\
\hline $5 \min$ & .42 & .37 & .41 & .26 & -.32 & .30 & -.50 & .32 \\
\hline day & .44 & .33 & .35 & .26 & -.25 & .29 & -.53 & .31 \\
\hline month & .43 & .31 & .49 & .24 & -.48 & .24 & -.45 & .30 \\
\hline
\end{tabular}

change in the stimuli and the manipulation of time delay between presentation and test. With regard to the material, 2 of the $40 \mathrm{fa}$ miliar musical selections were replaced here because a majority of subjects had judged them as being unfamiliar ${ }^{3}$ in Experiment 1. Otherwise, the task and procedure was identical to those in Experiment 1 for the two groups of subjects who performed the affect task or the recognition task within the same session (the 5-min condition). Four other groups of subjects performed the same tasks with a delay of either $24 \mathrm{~h}$ (the 1-day condition) or 40 days on an average (range, 26-55 days for the 1 -month condition) between the study and the test phases. The subjects who were scheduled for a second session performed two independent tasks in their initial session: the familiarity decision task, which represents the study phase of the melodies, and an unrelated task on speech segmentation, so as to disguise the connection between the first and second testing sessions. The second session included the music test phase only; instructions and materials were otherwise identical to those used in the 5-min delay condition. The subjects who performed the affect task were told that they were participating in an inquiry of musical taste for a future study, and the subjects who performed the recognition task were asked to identify the melodies that they had heard in the previous session.

The experiment used a $3 \times 2 \times 2 \times 2$ mixed factorial design. There were two between-subjects variables: time delay ( $5 \mathrm{~min}$, 1 day, and 1 month) and type of test (affect vs. recognition). The within-subjects variables were familiarity with the melodies (familiar vs. unfamiliar) and presentation (presented vs. nonpresented). Subgroups of 10 subjects each were randomly assigned to each tape (corresponding to Set $A$ and Set $B$ ) in each of the six groups defined by time delay and task. The number of subjects was slightly greater in the two groups who performed the affect task ( 23 subjects) and the recognition task ( 24 subjects) in the 1-month delay condition, because it was expected that some subjects would not be available for retest. It turned out that only 1 subject dropped out of the study. All the subjects were university students selected with the same criteria as those in Experiment 1. The subjects were tested individually and were paid for their participation.

\section{Results}

In the study phase, all six groups of subjects achieved a high rate of hits (above .90) and a low rate of FAs (below $.15)$. That is, familiar and unfamiliar melodies were considered as such by the subjects. There was no difference between groups in terms of prior knowledge of the musical excerpts $(F<1$, on the hits minus FAs scores).

Affect task. As can be seen in Table 2, in the 5-min condition, the observed performance pattern was highly similar to the one obtained in Experiment 1 under similar testing conditions but with different subjects. This was supported statistically. The subjects preferred the studied melodies over the nonstudied ones when these were unfamiliar $\left[t(19)=3.044, S E_{\mathrm{dm}}=0.05, p<.01\right.$, by a onetailed test on the $z$ transforms of the ratings, and $t(19)=$ $2.559, S E_{\mathrm{dm}}=0.07, p<.01$, on the priming scores], whereas they did not exhibit this preference bias for the familiar melodies. This differential pattern of liking as a function of prior exposure for unfamiliar and familiar melodies was supported by a significant interaction between presentation and familiarity $\left[F(1,19)=4.45, M S_{\mathrm{e}}=\right.$ $0.03, p<.05]$. The results obtained in the 5 -min condition thus replicate those of Experiment 1 and provide a baseline against which to measure the effect of time delay.

As can be seen in Table 2, after a 1-day period, essentially the same pattern as that observed after $5 \mathrm{~min}$ emerges. The subjects still exhibit evidence of an exposure effect for unfamiliar melodies $[t(19)=4.359$ and 4.340 , $S E_{\mathrm{dm}}=0.07$ and .06 , on $z$ scores and priming scores, respectively, $p<.001$ by a one-tailed test]. The interaction between familiarity and presentation again reaches significance $\left[F(1,19)=4.47, M S_{\mathrm{e}}=0.03, p<.05\right]$ in the 1-day delay condition. This is not, however, the case for the data collected after a 1 -month period. In the 1 -month condition, there is no longer evidence of an exposure effect $(F<1)$. The disappearance of the exposure effect was supported by a delay $\times$ presentation interaction $[F(2,60)=4.99$, $\left.M S_{\mathrm{e}}=0.05, p<.01\right]$, as revealed by the ANOVA computed over the three delay conditions.

One effect that remained unchanged across time delays is the systematic preference for familiar over unfamiliar melodies. The effect reached significance at each delay $\left[F(1,19)=47.24, M S_{\mathrm{e}}=0.28\right.$, after $5 \mathrm{~min}$; $F(1,19)=44.03, M S_{\mathrm{e}}=0.27$, after 1 day; and $F(1,22)=$ $65.69, M S_{\mathrm{e}}=1.65$, after 1 month; all $\left.p \mathrm{~s}<.001\right]$.

Recognition task. The recognition parameters are summarized in Figure 2. As can be seen, the pattern of results remains quite similar at each delay condition, with discriminability remaining higher for familiar than for unfamiliar music. The combined ANOVA computed over the three delay conditions confirmed the presence of a robust effect of familiarity $\left[F(1,61)=65.89, M S_{\mathrm{e}}=6.47\right.$, $p<.001]$ that did not interact with time delay $[F(2,61)=$ $\left.1.48, M S_{\mathrm{e}}=0.10\right]$. However, discriminability decreased over time, as attested by a main effect of time delay $[F(2,61)$ $\left.=5.99, M S_{\mathrm{e}}=0.18, p<.005\right]$. Nevertheless, even after a retention interval of 1 month, discriminability remains above chance level $\left[t(23)=8.857\right.$ and $4.363, S E_{\mathrm{dm}}=$ 0.07 and $0.06, p<.001$, for the familiar and unfamiliar melodies, respectively]. As in Experiment 1, slopes were found to be close to 1 and are compatible with the operation of a single process of familiarity, working at different levels of efficacy. Finally, the $\beta$ values (see the right panel of Figure 2) indicate an increased bias to respond old over time for the familiar set $\left[F(2,61)=6.02, M S_{\mathrm{e}}=\right.$ $0.03, p<.002]$, whereas the response bias to respond new for the unfamiliar set remains essentially unchanged across time delays $\left[F(2,61)=1.11, M S_{\mathrm{e}}=0.02\right.$, n.s.]. The presence of a shift of criterion over time for the familiar melodies only was confirmed by the presence of an inter- 


\section{DISCRIMINABILITY}

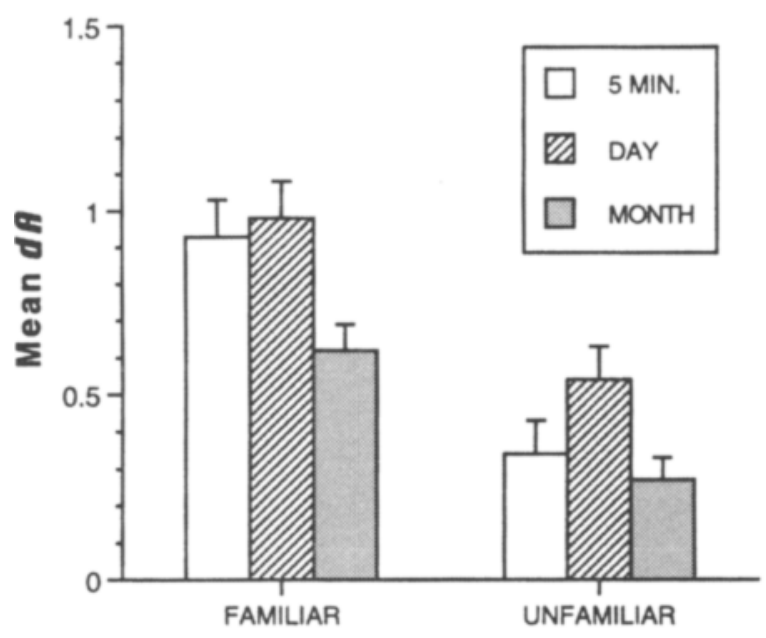

Music
CRITERION

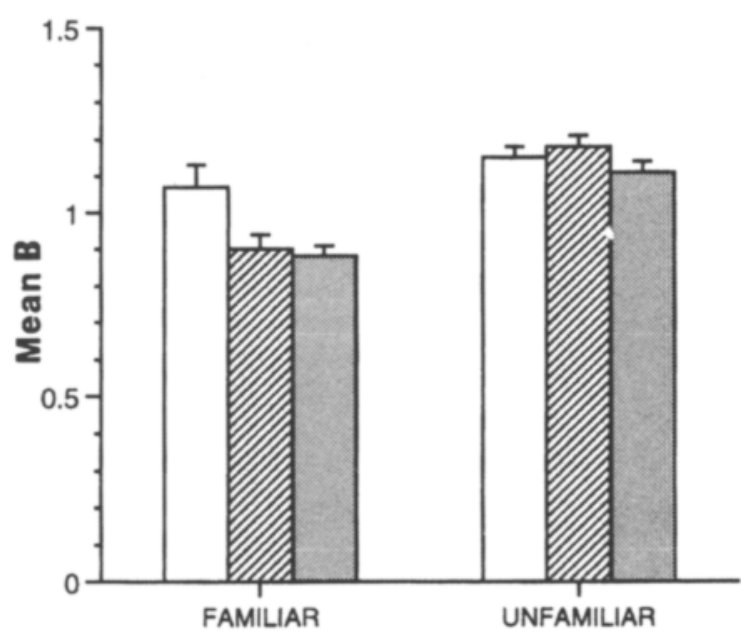

Music

Figure 2. Discriminability (left panel) and criterion measures (right panel) for the familiar and unfamiliar musical excerpts, derived from the recognition ratings obtained at each delay (5 min, 1 day, and 1 month) between study and test in Experiment 2. Error bars represent standard errors.

action between familiarity and delay $[F(2,61)=4.52$, $\left.M S_{\mathrm{e}}=0.02, p<.02\right]$.

\section{Discussion}

Manipulation of time delay between presentation and test provided further evidence for dissociable memorybased effects in affect and recognition. Memory effects were found to vanish on liking judgments over a 1-month period, whereas they remained sizable on recognition judgments over the same period. After a 1-month interval, the subjects were still able to discriminate studied from nonstudied melodies, while no longer showing a memory bias in likability for the same melodies. Note, however, that the dissociation between affect and recognition occurs in the opposite direction to that reported in the visual domain (Seamon et al., 1983).

Although the exposure effect on likability disappears after 1 month, it is not a shortlived phenomenon, since it emerged reliably after $24 \mathrm{~h}$. It is worth mentioning that 19 out of the 20 subjects exhibited a positive bias for the novel melodies that were studied the previous day. Thus, the phenomenon is robust and relatively long lasting (compared with most priming effects reported in the literature; see Roediger \& McDermott, 1993, for a review). However, it does not last for weeks, contrasting with what we found in Experiment 1. In that experiment, a weak but significant exposure effect was obtained after an interval of several months. One possible account for this discrepancy is that more than a single repetition may be necessary to produce long-lasting effects on liking judgments. The retesting procedure used in Experiment 1 involved two affect judgments of the same novel melodies, whereas only one opportunity for evaluation was provided in Experiment 2 . It may be the case that novel melodies need to be processed at least twice in order to get long-lasting exposure effects on preference. It is worth noting that, in Seamon et al.'s (1983) study, which reports persistence of exposure effects on liking judgments after 1 week, each visual stimulus was presented five times. Testing the frequency-affect relation over time for novel melodies should be a goal of future studies.

In contrast, recognition is found to be quite resistant to time. Although accuracy declines and the subjects increasingly confound preexperimental and experimental familiarity over time, the subjects are still able to discriminate the melodies from distractors after a period of 1 month. To our knowledge, this is the first demonstration of very long term memory for music, particularly for novel music that has been heard only once for a purpose other than memorization. This competence might be partly due to the fine-grained measurements taken in the present study, in which the subjects were required to rate their judgment on a 10-point scale. To examine this possibility, we dichotomized the responses, by considering each rating below 6 as new and above 5 as old for nonstudied and studied melodies, respectively. The resulting binary scores were found to be still above chance level in the 1 -month delay condition, with $66 \%$ correct for the familiar melodies [which is above the $50 \%$ chance level; $\left.t(23)=9.716, S E_{\mathrm{dm}}=0.00, p<.001\right]$ and $59 \%$ for the unfamiliar melodies $\left[t(23)=5.023, S E_{\mathrm{dm}}=0.00, p<\right.$ $.001]$. Thus, the evidence for long-term memory for the melodies cannot be entirely attributed to the fine-grained measure considered here and may well reflect the real competence of the majority of listeners.

At this stage, we can only speculate as to how subjects achieved such a good performance level in memory recognition. There is, however, a consensus regarding the 
familiar melodies. They are considered to be more easily retained, not only because they can be mapped onto preexisting stored representations, but also because they can activate associated information, such as genre and titles, that can in turn be embedded into a larger body of preexisting knowledge. Genre is not distinctive in the present series of experiments because all the melodies pertain to only a few popular categories, such as children songs, traditional French songs, and Christmas carols. In contrast, the associated lyrics or titles are distinctive, and actual recourse to such labeling strategies is very likely, since at least 30 out of the 40 familiar melodies used in the experiments elicited verbal associations by a large majority of subjects (Peretz et al., 1995). Moreover, the familiarity decision task used at study may have promoted consultation of these associative memories; finding a title for a musical excerpt may be used as a validation of familiarity. This associative encoding may account for the high recognition performance noted for familiar melodies. The use of verbal labels for the novel melodies is less likely. It may still be the case that the familiarity decision involved exploration of titles or lyrics compatible with the novel melodies and that this search was sufficiently effective to confer an episodic quality to the melodies. This possibility will be discussed further after considering the results of Experiment 3. In this experiment, the use of a verbal code was discouraged by orienting the subjects' attention away from labeling strategies and toward the surface characteristics of the melodies.

In summary, the present experiment replicated the results obtained in Experiment 1 and provided evidence for a different temporal gradient of memory loss for the affect and the recognition judgments. The faster decay of exposure effects in the affect task than in the recognition task was in the opposite direction to what was expected from prior visual work. Nevertheless, the fact that these two forms of memory, expressed in affect and recognition, decline differently with time adds further strength to the notion that they tap different memory components.

\section{EXPERIMENT 3}

Experiment 3 was designed to assess the hypothesis that affect judgments rely on perceptual records of the melodies, whereas recognition judgments rely on more abstract representations. To this aim, we manipulated surface properties of the melodies and study tasks.

Changes of surface properties between study and test were expected to influence performance in the affect task and have little impact on recognition performance. The rationale was that, if affect is proximal to the perceptual processing system, as is the case for most implicit repetition tests, changing the format between study and test should impair the exposure effect on liking. In contrast study-test changes in perceptual form of the stimuli should have less impact on recognition judgments, which are conceived as tapping more abstract forms of memo- ries. One obvious way to change the surface characteristics of melodies without changing their structural identity is to modify the instrument on which they are played. In the preceding experiments, the melodies were presented at study and test with a piano timbre. In the present experiment, half the melodies were presented on piano and half were played on flute in the study phase. At test, the melodies were either repeated with the same timbre (e.g., piano-piano) or were repeated with a different timbre (e.g., piano-flute). Timbre is tangential to music identity in that musical excerpts can be easily recognized or compared, despite changes in sound sources. However, there is generally a cost due to timbre changes, since same-timbre discrimination leads to better performance than does different-timbre discriminations (Radvansky, Fleming, \& Simmons, 1995; Wolpert, 1990). Therefore, timbre attributes may be assumed to be computed during the perceptual analysis of the musical input.

Manipulation of LOPs at study consisted in orienting subjects' attention either to surface attributes or to abstract attributes of the melodies. In the preceding experiments, the subjects' attention was oriented toward structural (abstract) features of the melodies by having them to classify the melodies as familiar or unfamiliar, both types of melodies being of the same style. Consultation of abstract representations of the melodies was further promoted by the stimuli, which were computer generated (in a sense analogous to having line drawings or pictures representing real objects), thus lacking the acoustic characteristics, such as variations in intensity and duration, that make them sound natural. The same familiarityencoding instruction was used in this experiment and corresponded to the higher level of processing. As a way to induce the subjects to attend to the surface attributes of the melodies, an instrument-encoding instruction was given to another group of subjects. At study, the subjects were simply required to indicate whether the melodies were played on piano or flute. Assuming that subjects use an elaborative code in recognition (such as labeling), encoding surface characteristics should impair performance, as compared with the familiarity encoding situation in which the use of labels is compatible with the familiarity decision. Thus, an effect of encoding task, particularly for the recognition of familiar melodies, was predicted.

To test these predictions, the melodies were played either on piano or on flute, and the subjects performed one of two study tasks: an instrument decision task or a familiarity decision task. After a 5-min delay, the subjects were required either to rate their liking of the melodies or to make explicit recognition judgments about the same melodies. In both test tasks, half of the melodies were presented in the study phase, whereas the other half were not; half of the studied melodies were presented with the same instrument (i.e., timbre) as during the study phase and half were played with a different instrument. In each instrument category, half the melodies were familiar, and half were unfamiliar. 
Table 3

Mean $z$ Score Transforms (and Standard Deviations) of the Subjects' Ratings in the Affect Task for the Familiar and Unfamiliar Musical Excerpts as a Function of Encoding Task and Timbre in Experiment 3

\begin{tabular}{|c|c|c|c|c|c|c|c|c|c|c|c|c|c|c|c|c|}
\hline \multirow[b]{4}{*}{ Encoding Task } & \multicolumn{8}{|c|}{ Familiar Music } & \multicolumn{8}{|c|}{ Unfamiliar Music } \\
\hline & \multicolumn{6}{|c|}{$\mathbf{P}$} & & & \multicolumn{6}{|c|}{$\mathrm{P}$} & \multirow{2}{*}{\multicolumn{2}{|c|}{ NP }} \\
\hline & \multicolumn{2}{|c|}{$\mathrm{S}$} & \multicolumn{2}{|c|}{$\mathrm{D}$} & \multirow[b]{2}{*}{$M$} & \multirow[b]{2}{*}{$S D$} & \multicolumn{2}{|c|}{ NP } & \multicolumn{2}{|c|}{$\mathrm{S}$} & \multicolumn{2}{|c|}{ D } & \multirow[b]{2}{*}{$M$} & \multirow[b]{2}{*}{$S D$} & & \\
\hline & $M$ & $S D$ & $M$ & $S D$ & & & $M$ & $S D$ & $M$ & $S D$ & $M$ & $S D$ & & & $M$ & $S D$ \\
\hline $\begin{array}{l}\text { Familiarity } \\
\text { Instrument }\end{array}$ & $\begin{array}{l}.38 \\
.33\end{array}$ & $\begin{array}{l}.36 \\
.48\end{array}$ & $\begin{array}{l}.41 \\
.22\end{array}$ & $\begin{array}{l}.34 \\
42\end{array}$ & $\begin{array}{l}.40 \\
28\end{array}$ & $\begin{array}{l}.31 \\
.38\end{array}$ & $\begin{array}{l}.36 \\
31\end{array}$ & $\begin{array}{l}.22 \\
.29\end{array}$ & $\begin{array}{l}-.29 \\
-24\end{array}$ & $\begin{array}{l}.27 \\
33\end{array}$ & $\begin{array}{l}-.29 \\
-27\end{array}$ & $\begin{array}{l}.31 \\
36\end{array}$ & $\begin{array}{l}-.29 \\
-.25\end{array}$ & $\begin{array}{l}.23 \\
.29\end{array}$ & $\begin{array}{l}-.47 \\
-34\end{array}$ & $\begin{array}{l}.28 \\
32\end{array}$ \\
\hline
\end{tabular}

Note-S, same timbre; D, different timbre; P, presented; NP, nonpresented

\section{Method}

Materials. The same 80 melodies, divided into Set $\mathrm{A}$ and Set $\mathrm{B}$ were used as in Experiment 2. The only difference was that there were two versions of each melody: one version using a simulated piano sound, and the other using a simulated flute sound. This was done so that timbre changes between study and test always included a change in the perceived instrument. We recorded eight tapes for the affect and recognition tasks so that (1) each of the 80 melodies appeared once on piano and once on flute; (2) each tape contained half of the familiar and unfamiliar melodies played on piano and the other half on flute; and (3) half of the studied melodies were repeated in the same timbre and half were changed to a different timbre at test.

Design and Procedure: The experiment used a $2 \times 2 \times 2 \times 2$ factorial design. There were two between-subjects variables: encoding task (familiarity vs. instrument) and type of test (affect vs. recognition), with initially 24 subjects in each of these four conditions. The number of subjects was subsequently increased to 32 in the two groups performing the affect task in order to increase the statistical power to detect an effect of timbre change. As in the previous experiments, the within-subjects variables were familiarity with the melodies (familiar vs. unfamiliar) and item presentation (presented vs. nonpresented). The new timbre (same vs. different) variable was also a within-subjects variable. However, its potential impact on the ratings can only be measured on the studied melodies. Thus, the effect of study-test changes in timbre was assessed in a separate ANOVA, considering only the ratings obtained for the studied melodies as the dependent variable. Eight subgroups of 3-4 subjects each were randomly assigned to each tape in each group defined by the combination of encoding task and test task. The subjects were tested individually.

Each subject first studied 40 melodies, either according to familiarity as in the previous experiments (familiarity-encoding task) or according to the instrument on which the melody was played (instrument-encoding task). In the instrument-encoding task, the subjects were required to provide a two-category decision by indicating for each stimulus whether it was produced by a piano or by a flute. To avoid suspicion, the subjects were told that, since some subjects cannot perform this simple task, control data were needed. After this study phase, an interval of about 5 min was filled with the instructions for the following test. The subjects were instructed to rate either their liking or their recognition judgments for each of the 80 test melodies, as in the previous experiments. All the subjects were required to rate the melodies and were told that any variation in timbre was irrelevant to the task.

\section{Results}

In the study phase, the two groups of subjects who performed the familiarity decision task at study achieved a high rate of hits (.88) and a low rate of FAs (below .13). The two groups who performed the instrument decision task achieved an almost perfect score (with $99.5 \%$ correct in each group). The average $z$ scores obtained for the subsequent affect judgments after familiarity-encoding and instrument-encoding instructions are presented in Table 3. The data obtained for the recognition judgments are presented in terms of $z$ scores in Table 4 and in terms of signal detection parameters in Figure 3.

Affect task. As can be seen in Table 3, an exposure effect was again observed on liking ratings for the unfamiliar melodies. The size of the effect did not vary much according to the encoding task, and there was no sizable effect of timbre changes between study and test. These observations were supported statistically.

The ANOVA computed on the $z$ scores with encoding task (familiarity vs. instrument decision) as the betweensubjects factor, and familiarity (familiar vs. unfamiliar melodies) and presentation (presented vs. unpresented melodies) as within-subjects factors, revealed once again a significant interaction between familiarity and presentation $\left[F(1,62)=8.52, M S_{\mathrm{e}}=0.03, p<.005\right]$, indicating the presence of an exposure effect limited to the unfamiliar musical set. There was no effect of encoding task $\left[F(1,62)=1.03, M S_{\mathrm{e}}=0.00\right.$, n.s. $]$, but there was the usual large effect of familiarity $\left[F(1,62)=110.95, M S_{\mathrm{e}}=0.26\right.$, $p<.001]$, showing that the subjects preferred the familiar over the unfamiliar melodies. There were no other significant effects or interactions.

To assess the effect of study-test changes in timbre, we performed another ANOVA with timbre (same vs. different) and familiarity (familiar vs. unfamiliar melodies) as within-subjects factors and encoding task (familiarity vs. instrument decision) as between-subjects factor on the $z$ score obtained for the studied melodies (see the $\mathrm{S}$ and D columns in Table 3 ). This analysis did not reveal any effect of timbre change $(F<1)$ or interaction with the other factors (all $F \mathbf{s}<1.2$ ). Thus, timbre change between study and test was not found to influence liking ratings in either condition.

Recognition task. The recognition data differ sharply from the affect results. Both encoding task and timbre change appear to affect the recognition scores. These effects were assessed by way of three separate ANOVAs, with the first two considering encoding task as the betweensubjects variable and familiarity as the within-subjects variable on $d_{a}$ and $\beta$ values, respectively (summarized in Figure 3 ). The third ANOVA, aiming at assessing the effect of study-test changes in timbre, was performed on 


\section{DISCRIMINABILITY}

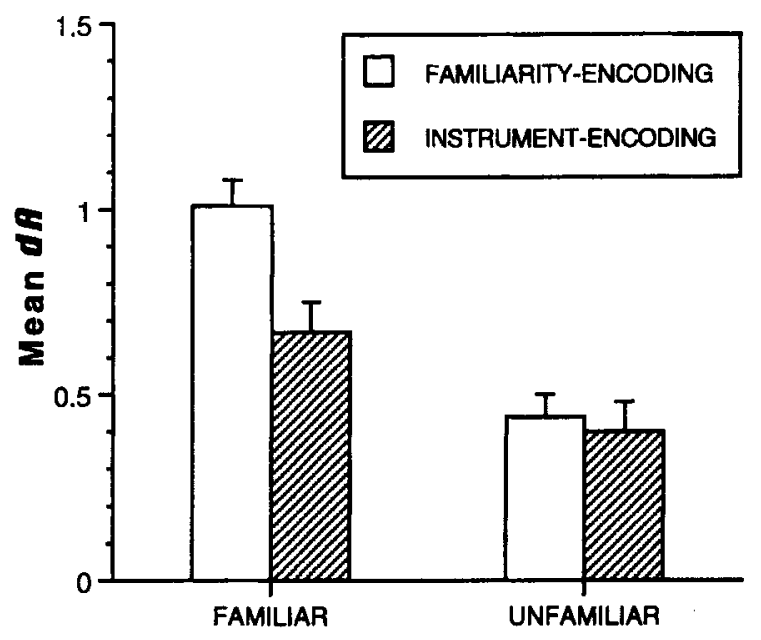

Music

\section{CRITERION}

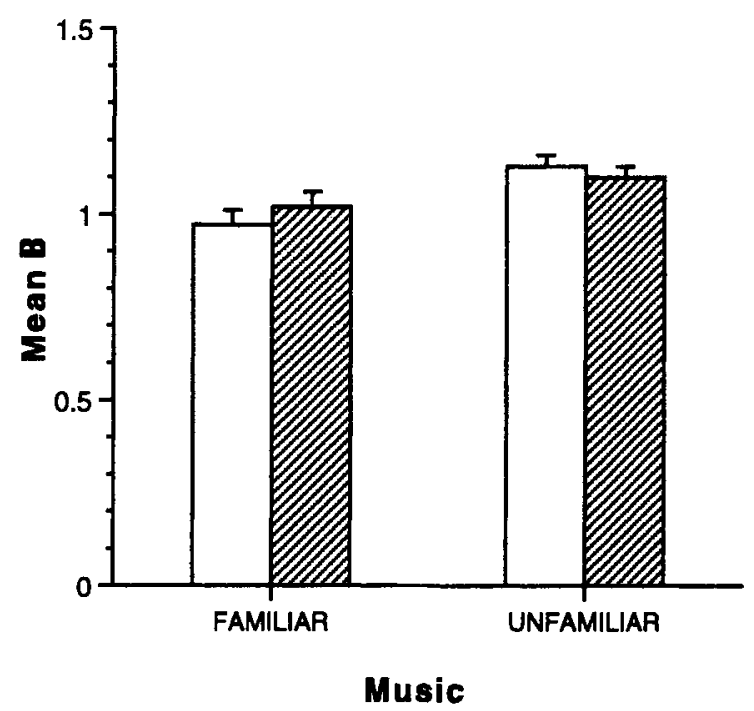

Figure 3. Discriminability (left panel) and criterion measures (right panel) for the familiar and unfamiliar musical excerpts, derived from the recognition ratings after the familiarity-encoding instruction and the instrument-encoding instruction in Experiment 3. Error bars represent standard errors.

the $z$ scores (summarized in Table 5), as was done for the affect task, because signal detection parameters cannot be derived in this case (i.e., there are only hits or misses and no FAs).

The first analysis performed on the $d_{a}$ measures yielded an encoding $\times$ familiarity interaction $[F(1,46)=7.11$, $\left.M S_{\mathrm{e}}=0.08, p<.02\right]$. Interestingly, manipulation of encoding task had a reliable effect on subsequent discriminability of the familiar melodies $(p<.001$, by Tukey post hoc comparisons) but none on the recognition of the unfamiliar melodies. Thus, the LOP manipulation was effective on recognition of familiar music. As in previous experiments, a significant effect of familiarity emerged across encoding tasks $\left[F(1,46)=54.61, M S_{\mathrm{e}}=0.08, p<\right.$ $.001]$, confirming the higher recognition scores obtained for familiar melodies, as compared with unfamiliar melodies. The slopes and the mean $\beta$ were very close to 1 in each condition, thus discarding changes of criteria as a potential source for the differences. The ANOVA computed on the $\beta$ scores did not reveal any effect of encoding instruction $(F<1)$ or interaction between encoding and familiarity $\left[F(1,46)=1.14, M S_{\mathrm{e}}=0.03\right.$, n.s. $]$. As in the preceding experiments, there was an effect of familiarity $\left[F(1,46)=12.72, M S_{\mathrm{e}}=0.03, p<.001\right]$, due to the presence of a bias to respond new for the unfamiliar melodies.

The effect of study-test changes in timbre on melody recognition was assessed with an ANOVA, taking timbre change and familiarity as the within-subjects factors and encoding task as the between-subjects factor, on the $z$ scores. As can be seen (by comparing the values in columns $S$ and $D$ of Table 4), same-timbre melodies were better discriminated than different-timbre melodies in all conditions. This was confirmed by a main effect of timbre $\left[F(1,46)=10.53, M S_{\mathrm{e}}=0.07, p<.002\right]$. This memory advantage for same-timbre over different-timbre melodies was general, in that it depended neither on prior familiarity with the material (the familiarity $\times$ timbre interaction yielding $F<1$ ) nor on the encoding task [the timbre $\times$ encoding interaction yielding $F(1,46)=1.81$, $M S_{\mathrm{e}}=0.07$, n.s.]. Thus, across encoding conditions, melodies were best recognized when they were presented with the same format at study and test.

\section{Discussion}

The major finding in Experiment 3 is that exposure effects on liking judgments appear immune to experimental manipulations that, in contrast, have a marked impact on recognition judgments. The exposure effects in the affect task resemble those observed in Experiments 1 and 2, despite the changes made to the melodies and those induced by the study task. Changing the timbre of the melodies between study and test and changing the focus of attention while encoding the melodies left the memory effects in the affect task unchanged. The observation that both new variables - timbre change and encoding task - had a profound impact on recognition judgments provides strong support for the view that the memory effects observed in recognition and affect are qualitatively different.

Some of these results were predicted and are consistent with the existing literature on implicit and explicit memory for nonmusical material, and some of the results are divergent. One similarity with the literature is that LOP manipulation was found to influence recognition (explicit memory) and not affect (implicit memory). The subjects 
Table 4

Mean $z$ Score Transforms (and Standard Deviations) of the Subjects' Ratings in the Recognition Task for the Familiar and Unfamiliar Musical Excerpts as a Function of Encoding Task and Timbre in Experiment 3

\begin{tabular}{|c|c|c|c|c|c|c|c|c|c|c|c|c|c|c|c|c|}
\hline \multirow[b]{4}{*}{ Encoding Task } & \multicolumn{8}{|c|}{ Familiar Music } & \multicolumn{8}{|c|}{ Unfamiliar Music } \\
\hline & \multicolumn{6}{|c|}{$P$} & & & \multicolumn{6}{|c|}{$\mathrm{P}$} & & \\
\hline & \multicolumn{2}{|c|}{$\mathrm{S}$} & \multicolumn{2}{|c|}{$\mathrm{D}$} & \multirow[b]{2}{*}{$M$} & \multirow[b]{2}{*}{$S D$} & \multicolumn{2}{|c|}{ NP } & \multicolumn{2}{|c|}{$\mathrm{S}$} & \multicolumn{2}{|c|}{ D } & \multirow[b]{2}{*}{$M$} & \multirow[b]{2}{*}{$S D$} & \multicolumn{2}{|c|}{ NP } \\
\hline & $M$ & $\overline{S D}$ & $M$ & $\overline{S D}$ & & & $M$ & $S D$ & $M$ & $S D$ & $M$ & $\overline{S D}$ & & & $M$ & $S D$ \\
\hline Familiarity & .93 & .34 & .69 & .35 & .81 & .27 & -.41 & .32 & .13 & .39 & .01 & .32 & .07 & .29 & -.46 & .26 \\
\hline Instrument & .68 & .34 & .60 & .36 & .64 & .28 & -.26 & .32 & .05 & .33 & -.02 & .34 & .02 & .28 & -.40 & .27 \\
\hline
\end{tabular}

Note-S, same timbre; D, different timbre; P, presented; NP, nonpresented.

were less accurate in recognizing the familiar melodies after having paid attention to their surface features, following the instruction to judge the instrument on which they were produced, than after having paid attention to their structural features, following the instruction to judge their familiarity with the melodies. This effect of LOP lends support to the view that explicit memory for music is best when subjects are induced at study to make contact with their prior knowledge of the music. When such elaborative or associative encoding is compromised by the instruction to direct attention toward the musical instrument, recognition memory drops considerably. These conclusions are very similar to the ones drawn in other domains. In word memory, it has been repeatedly shown that subjects who study words semantically (e.g., by judging the pleasantness of each word) have better recall performance than those who study the words perceptually (e.g., by judging the number of vowels contained in each word). This LOP effect on word recall is highly robust and contrasts with its lack of (or weak) influence on (implicit) word stem completion (Graf \& Mandler, 1984; Graf, Mandler, \& Haden, 1982; Java \& Gardiner, 1991; Light \& Singh, 1987; Lupker, Harbuk, \& Patrick, 1991; Micco \& Masson, 1991; Nelson, Shreiber, \& Holley, 1992; Park \& Shaw, 1992; Roediger, Weldon, Stadler, \& Riegler, 1992; Schacter \& Church, 1992; Squire, Shimamura, \& Graf, 1987).

One important divergence with word memory is that changes in timbre attributes did not influence the (implicit) affect judgments but did so for (explicit) recognition of the melodies. Using auditory words, Schacter and Church (1992) have shown the opposite-that is, changes in the speaker's voice have a modest but reliable adverse effect on performance in the (implicit) stem completion task, whereas they have no effect on explicit cued recall of the same words. This voice effect has been further refined and replicated in more recent studies (Church \& Schacter, 1994; Goldinger, 1996). Given that both tasks and materials were different in the present study, it is difficult to identify the parameters that may account for this rather important difference between auditory memory for words and that for music.

However, it must be pointed out that the data observed here for timbre changes are highly consistent with the work done on memory for visual objects. Visual objects that are transformed by surface changes in left-right ori- entation or in size have been found to impair explicit, not implicit, performance (Biederman \& Cooper, 1992; Cave \& Squire, 1992; Cooper, Schacter, Ballesteros, \& Moore, 1992; Schacter, Cooper, \& Teadwell, 1993). A similar dissociation has been reported with the affect and recognition tasks. Seamon et al. (1997) have shown that recognition, not affective preference, was impaired by reflection or size transformations of visual objects between study and test, much in the same way as timbre change was found to impair recognition but not liking judgments.

The visual results have been taken to suggest that physical attributes (e.g., size) that do not alter object shape representation do not influence repetition priming, including the mere exposure effect on liking, because repetition priming is not a low-level sensory facilitation phenomenon but is instead a reflection of higher level object processing. In contrast, physical attributes are viewed as information that is bound to a given object in order to provide a distinct temporal-spatial context (episodic-like quality) to the object. Forming such new associations between surface attributes and shapes would fulfill the role of episodic memory. By analogy, the present results may suggest that the memory representations underlying the mere exposure effect observed in music preference contain abstract features that are essential for determining melody identity. In contrast, memory representations that subserve explicit recognition would be formed by new associations binding together timbre characteristics and melody identity. These suggestions are obviously ad hoc and require direct evaluation.

In a fourth experiment, we probed more directly the content of these episodic memories for the melodies, while keeping task parameters constant. We tested two new groups of subjects and simply added an instrument recognition judgment at test. That is, after incidental study of the musical material, the subject's task was to recognize, as in the present Experiment 3, whether the melody had been presented before and, when affirmative, whether the melody had been presented using that same instrument. For melody identity recognition, we replicated the results obtained here. For instrument recognition, the subjects performed poorly, with $54.2 \%$ correct. Nevertheless, this score was above chance performance [being $\left.50 \% ; t(46)=2.967, S E_{\mathrm{dm}}=0.01, p<.01\right]$. Thus, subjects are able, to some extent, ${ }^{4}$ to deliberately retrieve timbre information in memory, thereby supporting the view 
that the timbre of the studied melody is part of the episodic record and, thus, is available for subsequent recognition.

Finally, it is worth mentioning one aspect of the timbre effects obtained on recognition (see Table 4 ). The subjects recognized same-timbre repetitions more accurately than they did different-timbre repetitions, even when they were discouraged from considering timbre information. In the familiarity-encoding condition, neither at study nor at test were the subjects told that timbre might influence their behavior in any way. Yet, a large influence on the recognition of old melodies was detected as dependent on the timbre status. Melodies that remained in the same timbre from study to test were recognized better than were old melodies that were different in timbre at study and test. The timbre effect was at least as large as the one obtained by the subjects who did pay attention to timbre at study because they received the instrumentencoding instruction. This suggests that consideration of timbre is not modulated by attention allocation but instead may be computed automatically. These computations may not be critical for melody identity and, hence, for likability but may well be critical to episodic memory for melodies.

\section{GENERAL DISCUSSION}

This set of experiments has yielded a number of new experimental dissociations between implicit and explicit memory in the auditory musical domain. Experiments 1, 2 , and 3 showed that prior knowledge of the melodies differentially influenced memory effects in liking and recognition judgments. Experiments 1 and 2 showed that these memory effects are not simply ephemeral, in that they last for more than 1 full day, although they exhibit a different temporal gradient in the two kinds of judgments. Experiment 3 showed that LOP at encoding has an impact on recognition performance but none on liking judgments. Finally, Experiment 3 revealed that recognition judgments, but not affect judgments, are impaired by changes in surface features of the melodies. From these results arise a number of empirical and theoretical issues that will be considered in turn.

The first major conclusion to be drawn from these results is that the affect and recognition tasks reflect the involvement of implicit and explicit memory processes, respectively, as was formerly demonstrated by Seamon et al. (1995) in the visual domain. The tests satisfy the two criteria of retrieval intentionality enunciated by Schacter and his collaborators (Schacter et al., 1989). First, the affect and recognition tests employed the same study and test materials, thus providing the same external cues to subjects in both tasks. Only the instructions varied at test, with the recognition task requiring intentional retrieval of the study episode, whereas the affect task did not. Yet, in each task, a reliable effect of prior study of melodies could be found on their subsequent treatment. These effects of prior exposure can thus be attributed to the working of intentional retrieval in the case of recognition and of implicit memory in the case of preferences. Secondly, as is summarized above, a number of experimental variables were found to dissociate the two forms of memory effects. In general, the memory effects in recognition were found to be flexible, in that they could be modulated by experimental treatments. In contrast, the memory effects remained essentially fixed in regard to affect. Recognition memory was found to decline over time (Experiments 1 and 2) and to be sensitive to LOPs at encoding and to the surface match between study and test (Experiment 3). For preferences, the memory effects remained stable throughout these treatments, with one exception. Insertion of a month delay between study and test succeeded in reducing the preference bias for the studied melodies to baseline (Experiment 2). In Experiment 1, however, insertion of several months between test and retest did not cancel out the preference bias. This discrepancy between Experiments 1 and 2 may be related to frequency of exposure, which was slightly higher in the first experiment. Future studies should aim at verifying this possibility, since it concerns the only occasion on which exposure effects were found to be influenced by task factors.

Altogether, the results suggest that affect judgments function in an obligatory fashion. This obligatory mode of functioning is what should be expected from an implicit system that operates in a largely unconscious, automatic mode. In contrast, recognition memory appears flexible and fits with the notion that it is the product of an adaptive, controlled system, as is expected from explicit memory. This conclusion is highly consistent with the results of Johnson et al. (1985), which showed that amnesia spares the memory effects in affect judgments and reduces explicit memory recognition for melodies. The present results extend this neuropsychological dissociation between implicit and explicit memory to neurologically intact subjects.

The experimental dissociations observed here between the two forms of memory relied on a number of different variables, of which some - study-test time delay, LOP - are known to differentially influence implicit and explicit memory in other domains. Other variables are somewhat new-familiarity with melodies, study-test changes in timbre-in that they have not yet been exploited in past research. Accordingly, some of the results provide new converging evidence for the distinction between implicit and explicit memory in the auditory domain, whereas others, by being divergent from the dominant pattern in the literature, raise questions as to the nature of the memory representations that are tapped by music preference and recognition. The specific impact of each manipulated factor will be discussed in turn. In doing so, we will address the possibility that the memory effects under study are specific to the musical domain.

Familiarity with melodies was a key manipulation in the present study. Prior knowledge of the music systematically dissociated recognition from liking judgments (Experiments 1,2, and 3). The subjects excelled at discriminating studied from nonstudied familiar melodies 
in the recognition task, whereas they liked them equally in the affect task. This result suggests that affect judgments are not governed by explicit retrieval strategies for the studied material. The pattern was recurrent, emerging in each experiment involving six different groups of subjects. For the melodies that were unfamiliar preexperimentally, the subjects exhibited parallel memory-biased performance in the two tasks, by an increase in their liking for just those melodies that were presented in the study phase and by discriminating them from among unfamiliar distractors of the same style. The fact that the subjects displayed parallel exposure effects for the unfamiliar melodies in both recognition and affect does not entail that these memory effects have the same origin. As will be described further below, exposure effects on the unfamiliar portion of the material were differentially sensitive to time delay between study and test, to LOPs, and to timbre changes, depending on the task considered.

The effect of familiarity on preference is probably not specific to music. The observation that repetition of familiar melodies does not further increase their overall preference level is consistent with the literature on nonmusical stimuli. In general, exposure effects on liking are maximal after a few presentations and reach a plateau after about 10 presentations (Bornstein, 1989). This plateau had certainly been reached with the highly familiar melodies that were selected here as stimuli, although this plateau had been reached prior to and outside the actual experimental setting. Processing of these melodies had been a highly practiced activity over the course of several years, if not decades, since most of these melodies had been learned during childhood (Peretz et al., 1995). Thus, a supplementary exercise provided at study in the laboratory will not result in a noticeable increase in preference, compared with the nonstudied but equally overlearned melodies. However, this preexperimental familiarity will lead to an overall preference effect for the familiar melodies over novel melodies in the experimental setting, as observed in the three experiments. Generally, the subjects liked familiar melodies better than novel ones, even when the latter benefited from prior exposure in the experimental situation. This preference bias is similar to what has been observed for flowers, fruits, and common names; when these items possess preexperimental representations, they yield the most robust effects of preference (see Bornstein for a review). Note, however, that in none of these earlier studies have familiar and unfamiliar items been directly compared within the same preference situation.

Prior knowledge of the melodies may not be the sole factor responsible for their general preference. Another plausible factor may be the internal structure of the familiar melodies, which had made them ubiquitous to the French musical culture. It may be the case that the unfamiliar melodies that we selected on the basis of their relative obscurity remained such because they are structurally poorer than the familiar melodies..$^{5}$ Accordingly, the overall preference for familiar melodies may be re- lated to their greater musicality. For instance, it has been shown that Western listeners prefer musical stimuli that are most typical in terms of the tonal structure of their musical idiom (Cross, Howell, \& West, 1983; Smith \& Melara, 1990). Teasing apart the contribution of familiarity from musicality on liking judgments should be the goal of future studies. In the present context, it is important to keep in mind that the unfamiliar (or obscure) melodies were found to be discriminable in terms of likability, hence providing an adequate pool of stimuli with which to study implicit memory effects for music.

Similarly, in the recognition task, one may ask whether familiar melodies were better recognized because they are more musical or because they benefit from more elaborative encoding due to their preexisting representations. Although we cannot provide a definite answer to this question, prior studies seem to favor the elaborative encoding interpretation (Bartlett et al., 1995; Java et al., 1995; Peretz, 1996). In Bartlett et al.'s study, musicality was controlled by presenting novel melodies that had been purposely composed for the experiment and selected for their matched musicality with the familiar melodies. The subjects nevertheless recognized the familiar melodies better than the novel ones. Thus, the memory advantage for the familiar over the novel melodies appears related to the existence of prior memory traces rather than to a putative well-formedness factor. Access and recourse to efficient elaborative codes, such as verbal labels, were particularly likely in the present study, because the familiar melodies have been shown to easily evoke verbal associations in a former study (Peretz et al., 1995). Verbal associations are not the only basis for the familiar music advantage; the quality of the stored representations for familiar melodies may also confer such a memory advantage. For instance, it has been demonstrated that pitch information is more precisely represented in familiar melodies than in novel melodies (Attneave \& Olson, 1971; Bartlett \& Dowling, 1980; Dowling \& Fujitani, 1971). Thus, both the quality of the stored melodic representations and the availability of associative memories are likely to be responsible for the large memory advantage of familiar melodies.

From this account of the familiarity advantage in memory, one would expect that preventing subjects from being fully engaged at the associative encoding level of the melodies would result in a reduction of this advantage. This is precisely what has been observed in Experiment 3 . The familiar melodies were less well recognized when the subjects' attention was oriented toward the instrument on which they were played than when the subjects' attention was focused on familiarity at encoding. This effect of encoding instruction on subsequent memory performance refers to the LOP manipulation that is widely used in memory research. The conclusions are very similar to the ones drawn in other auditory domains. It has been repeatedly shown that subjects who study words semantically (e.g., by judging the pleasantness of each word) or perceptually (e.g., by judging the clarity of the 
pronunciation) recall the studied words encoded semantically better (Schacter \& Church, 1992; Schacter, Church, \& Treadwell, 1994). This LOP effect on explicit memory contrasts with its lack of (or weak) influence on (implicit) word stem completion or word identification (Schacter \& Church, 1992; Schacter, Church, \& Treadwell, 1994). Similar LOP effects have been observed for familiar environmental sounds (Chiu \& Schacter, 1995). The present study extends this principle to the case of melodies.

One apparent difficulty with this account of the explicit memory effects in terms of the use of abstract codes is the finding that recognition performance is sensitive to the perceptual format of the melodies. The subjects better recognized melodies when they were repeated in the same timbre as that used at study than when the melodies were repeated using a different timbre. This effect of timbre matching on recognition is problematic, because explicit memory is expected to rely on abstract rather than surface melodic features. Moreover, neither the material nor the task demands emphasized the surface aspects of the melodies. The stimuli were already relatively abstract by being computer generated while referring to melodic lines that are normally sung with lyrics. Task demands required recognition of the melodies, not the instrument on which they were played (Experiment 3). When instructions did orient the subjects' attention toward the instrument characteristics, by requiring an instrument decision at study, timbre variations weakened performance to the same extent as when the subjects did not pay attention to this feature when encoding the melodies (i.e., when performing a familiarity decision). Thus, consideration of timbre in melody recognition appears to be automatic. However, retrieval of timbre information appears, to some extent, to be under conscious control. In a subsequent experiment, the subjects were shown to be capable of retrieving, above chance, the instrument on which the melodies were initially played, even though both encoding and recognition emphasized melodic over timbre information.

The ensuing question is why did the subjects pick up on timbre and use it at retrieval when explicit memory was probed and not when implicit memory was. The most reasonable account that we can provide at this stage is the one offered in the visual domain, where similar effects have been reported (Cave, Bost, \& Cobb, 1996; Seamon et al., 1997; Snodgrass, Hishman, \& Fan, 1996). By this account, the primary role of explicit memory is to code the distinctive spatiotemporal context of a presented object so as to differentiate it from other, similar objects in memory. Accordingly, sensory features are stored in episodic memory along with the object, so as to create distinctive newly formed associations. Thus, timbre would be stored as contextual information for the presented melody, so as to confer to the studied event a distinct episodic-like quality. Perhaps musical timbre enjoys a special status in this regard by being one of the few musical attributes that can be used for the purpose of recollection. By this view, timbre and melody would be com- puted separately and linked together in episodic memory, so as to provide a unified recollection of the studied event.

Note, however, that this interpretation derived from visual studies is at variance with other data gathered in the auditory modality. Changes in surface features of words through speakers' voice characteristics have been shown to impair implicit memory, not explicit memory (Church \& Schacter, 1994; Schacter \& Church, 1992), hence giving rise to the opposite pattern. It may be premature to conclude from this discrepancy that memory organization differs for verbal and musical domains. One can conceive how timbre manipulation may succeed in biasing melody preference. For example, making the timbre more relevant to the liking judgments, by singing the melody in an agreeable voice or in a familiar voice, may change the results. Thus, the absence of a timbre effect on affect may not be absolute but dependent on the relevance to the task. On the other hand, the factors that are responsible for the voice-specific effects in implicit memory for words are not yet fully understood. Voice-specific effects are not found systematically (see, e.g., Schacter, Church, \& Bolton, 1995; Schacter, Church, \& Osowiecki, 1994 ) and are currently the object of intensive work (see, e.g., Goldinger, 1996; Schacter \& Church, 1995).

One final new outcome of the present study concerns the longevity of recognition memory for melodies. Russel (1987) had already shown that subjects were able to recognize 20 short pieces of modern jazz from among distractors of the same style 1 week later. As is shown here, this memory capacity can be extended to 40 melodies and to a 1-month period. It is probable that not all melodies are evoking the same sense of acute memory, which appears to be distributed on a continuum of memory strength. One interesting avenue for future research is to further fractionate this memory capacity for melodies into one component based on conscious recollection of the studied melodies and another based on feelings of familiarity, following the current view that recognition memory judgments involve these two components (Jacoby \& Dallas, 1981; Mandler, 1980; Tulving, 1985). Recollection is assumed to be an all-or-none retrieval process; successful retrieval is expected to lead to a highly confident response. Familiarity, on the other hand, is conceived as a continuous process. Both processes would contribute independently to overall recognition performance. Evidence for this dual process of recognition memory should be apparent in the ROC curves derived from the application of the signal detection theory, following Yonelinas (1994). However, in none of the experiments did we find support for this view, the curves being most consistent with the intervention of a single process of memory strength. Nevertheless, Java et al. (1995) successfully distinguished between these two forms of awareness states in melody recognition by requiring subjects to classify their recognition judgments into remember and know responses (following Tulving's procedure). Familiar musical themes evoked mostly remember responses, whereas unfamiliar 
ones were more often associated with know responses. It would be worthwhile to compare remember and know responses in recognition conditions that are derived from the present set of studies. By studying the effects of time delay, of study tasks, and of study-test changes in timbre, we would be in a position to further qualify recognition memory for melodies and, above all, to understand better the nature of the familiarity component underlying its efficiency.

In summary, we have learned a great deal about the functioning of recognition memory for melodies, but we still know little about the functioning of the mere exposure effect. In line with almost a century of empirical observations (e.g., Meyer, 1903), the mere exposure effect, which refers to the increase in liking due to prior exposure, was found to be a reliable and robust phenomenon. Although it is a simple phenomenon to describe and to induce experimentally, it is less easy to explain. The mere exposure effect is clearly a memory phenomenon that can be dissociated from explicit recognition. As a memory phenomenon, the mere exposure effect must depend on some form of representation stored between previous encounters with a melody and the repeated experience of it. Attempting to identify the nature of these representations was one of the major goals of the present study. In line with Tulving and Schacter's (1990; Schacter \& Tulving, 1994) proposal and following our previous work with patients having sustained brain damage (Peretz, 1996), we posited that the initial encoding of a melody creates, or activates, a representation in a perceptual representation system that is specific to music. This representation is expected to facilitate its subsequent processing, which would be attributed by the subject to an increase in liking. Although the results are compatible with this view, they do not provide supportive evidence.

\section{REFERENCES}

Attneave, F., \& Olson, R. (1971). Pitch as a medium: A new approach to psychophysical scaling. American Journal of Psychology, 84, 147 166.

Bartlett, J., \& Dowling, J. (1980). The recognition of transposed melodies: A key-distance effect in development perspective. Journal of Experimental Psychology: Human Perception \& Performance, 6, 501-515.

Bartlett. J., Halpern, A., \& Dowling, J. (1995). Recognition of familiar and unfamiliar melodies in normal aging and Alzheimer's disease. Memory \& Cognition, 23, 531-546.

Bassili, J. N., SMith, M. C., \& MACLeod, C. M. (1989). Auditory and visual word-stem completion: Separating data-driven and conceptually driven processes. Quarterly.Journal of Experimental Psychologv, 41A, 439-453.

Berthier, J. E. (1979). 1000 chants. Paris: Les Presses de l'Ile-de-France. Biederman, R., \& CoOper, L. (1992). Size invariance in visual object priming. Journal of Experimental Psychology: Human Perception \& Performance, 18, 121-133.

BornsteIn, R. (1989). Exposure and affect: Overview and meta-analysis of research 1968-1987. Psychological Bulletin, 106, 265-289.

Bornstein, R., \& D'Agostino, P. (1994). The attribution and discounting of perceptual fluency: Preliminary tests of a perceptual fluency/attributional model of the mere exposure effect. Social Cognition, 12, 103-128.

Brickman, P., Redfield, J., Harrison, A., \& Crandall, R. (1972).
Drive and predisposition as factors in the attidudinal effects of mere exposure. Journal of Experimental Social Psychology, 8, 31-44.

Carlesimo, G. A., Marfia, G. A., loasses, A., \& Caltagirone, C. (1994). Perceptual and conceptual components in implicit and explicit stem completion. Neuropsychologia, 34, 785-792.

Cave, C. B., Bost, P. R., \& CoBB, R. E. (1996). Effects of color and pattern on implicit and explicit picture memory. Journal of Experimental Psychology: Learning, Memory, \& Cognition, 22, 639-653.

CAVE, C. B., \& SQuire, L. R. (1992). Intact and long-lasting repetition priming in amnesia. Journal of Experimental Psychology: Learning, Memory, \& Cognition, 18, 509-520.

ChIU, C.-Y., \& SCHACTER, D. L. (1995). Auditory priming for nonverbal information: Implicit and explicit memory for environmental sounds. Consciousness \& Cognition, 4, 440-458.

ChurCh, B. A., \& Schacter, D. L. (1994). Perceptual specificity of auditory priming: Implicit memory for voice intonation and fundamental frequency. Journal of Experimental Psychology: Learning, Memory, \& Cognition, 20, 521-533.

Cooper, L. A., Schacter, D. L., Ballesteros, S., \& Moore, C. (1992). Priming and recognition of transformed three-dimensional objects: Effects of size and reflection. Journal of Experimental Psychology: Learning, Memory, \& Cognition, 18, 43-57.

Craik, F., Moscovitch, M., \& MCDowd, J. (1994). Contributions of surface and conceptual information to performance on implicit and explicit memory tasks. Journal of Experimental Psychology: Learning, Memory, \& Cognition, 20, 864-875.

Cross, I., Howell, P., \& West, R. (1983). Preferences for scale structure in melodic sequences. Journal of Experimental Psychology: Human Perception \& Performance, 9, 444-460.

Dorfman, D. D., \& ALF, E., JR. (1969). Maximum likelihood estimation of parameters of signal detection theory and determination of confidence interval-rating-method data. Journal of Mathematical Psychology, 6, 487-496.

Dowling, J., \& FuJiTANI, D. (1971). Contour, interval, and pitch recognition in memory for melodies. Journal of the Acoustical Society of America, 49, 524-531.

Ellis, H., Shepherd, J., \& Davies, G. (1979). Identification of familiar and unfamiliar faces from internal and external features: Some implications for theories of face recognition. Perception, 8, 431-439.

Gilliland, A., \& MoOre, H. (1924). The immediate and long-time effects of classical and popular phonograph selections. Journal of Applied Psychology, 8, 309-323.

GOLDINGER, S. (1996). Words and voices: Episodic traces in spoken word identification and recognition memory. Journal of Experimental Psychology: Learning, Memory, \& Cognition, 22, 1166-1183.

Graf, P., \& MANDLER, G. (1984). Activation makes words more accessible, but not necessarily more retrievable. Journal of Verbal Learning \& Verbal Behavior, 23, 553-568.

Graf, P., Mandler, G., \& Haden, P. E. (1982). Simulating amnesic symptoms in normals. Sciences, 218, 1243-1244.

Green, D. M., \& SweTS, J. A. (1966). Signal detection theory and psychophysics. New York: Wiley. (Reprinted 1974 by Krieger, Huntington, New York)

Greve, K. W., \& Bauer, R. M. (1990). Implicit learning of new faces in prosopagnosia: An application of the mere exposure paradigm Neuropsychologia, 28, 1035-1041.

Heingart Ner, A., \& Hall, J. (1974). Affective consequences in adults and children of repeated exposure to auditory stimuli. Journal of Personality \& Social Psychology, 29, 719-723.

HEYDUK, R. G. (1975). Rated preference for musical compositions as it relates to complexity and exposure frequency. Perception \& Psychophysics, 17, 84-90.

JACOBY, L. L., \& DAllas, M. (1981). On the relationship between autobiographical memory and perceptual learning. Journal of Experimental Psychology: General, 110, 306-340

JACOBY, L. L., \& KeLleY, C. M. (1987). Unconscious influences of memory for a prior event. Personality \& Social Psychology Bulletin, 13, 314-336.

JAVA, R., \& Gardiner, J. (1991). Priming and aging: Further evidence of preserved memory function. American Journal of Psychology, 104, 89-100. 
JAVA, R., KAMINSKA, Z., \& GARDINER, J. (1995). Recognition memory and awareness for famous and obscure musical themes. European Journal of Cognitive Psychology, 7, 41-53.

Johnson, M., KIM, J., \& Risse, G. (1985). Do alcoholic Korsakoff's syndrome patients acquire affective reactions? Journal of Experimental Psychology: Learning, Memory, \& Cognition, 11, 22-36.

KLATZKY, R. L., \& FORREST, F. H. (1984). Recognizing familiar and unfamiliar faces. Memory \& Cognition, 12, 60-70.

Krugman, H. (1943). Affective responses to music as a function of familiarity. Journal of Abnormal \& Social Psychology, 38, 388-392.

Lieberman, L., \& WALTERs, W. (1968). Effects of repeated listening on connotative meaning of serious music. Perceptual \& Motor Skills, 26, 891-895.

LIGHT, L., \& SiNGH, A. (1987). Implicit and explicit memory in young and older adults. Journal of Experimental Psychology: Learning, Memory, \& Cognition, 13, 531-541.

Lupker, S., Harbuk, J., \& Patrick, A. (1991). Memory for things forgotten. Journal of Experimental Psychology: Learning, Memory, \& Cognition, 17, 897-907.

MacMillan, N. A., \& Creelman, C. D. (1991). Detection theory: A user's guide. Cambridge: Cambridge University Press.

MANDLER, G. (1980). Recognizing: The judgment of previous occurrence. Psychological Review, 87, 252-271.

MANDleR, G., NAKamura, Y., \& VAN ZandT, B. (1987). Nonspecific effects of exposure to stimuli that cannot be recognized. Journal of Experimental Psychology: Learning, Memory, \& Cognition, 13, 646-648.

Marsolek, C. J., Kosslyn, S. M., \& SQuire, L. R. (1992). Form-specific visual priming in the right cerebral hemisphere. Journal of Experimental Psychology: Learning, Memory, \& Cognition, 18, 492-508.

MEYER, M. (1903). Experimental studies in the psychology of music. American Journal of Psychology, 14, 456-478.

Micco, A., \& MASSON, M. (1991). Implicit memory for new associations: An interactive process approach. Journal of Experimental Psychology: Learning, Memory, \& Cognition, 17, 1105-1123.

MOORE, T. (1914). The genetic aspect of consonance and dissonance. Psychological Monographs (Whole No. 73).

Moscovitch, M., VRIezen, E., \& Goshen-Gottstein, Y. (1993). Implicit tests of memory in patients with focal lesions or degenerative brain disorders. In H. Spinnler \& F. Boller (Eds.), Handbook of neuropsychology (Vol. 8, pp.133-173). Amsterdam: Elsevier.

MuLL, H. (1957). The effect of repetition upon enjoyment of modern music. Journal of Psychology, 43, 155-162.

Nelson, D. L., Shreiber, T. A., \& Holley, P. E. (1992). The retrieval of controlled and automatic aspects of meaning on direct and indirect tests. Memory \& Cognition, 20, 671-684.

PARK, D., \& SHAW, R. (1992). Effect of environmental support on implicit and explicit memory in younger and older adults. Psychology \& Aging, 7, 632-642.

Peretz, I. (1996). Can we lose memory for music? A case of music agnosia in a nonmusician. Journal of Cognitive Neuroscience, 8,481 496.

Peretz, I., Babaï, M., Lussier, I., Hébert, S., \& Gagnon, L. (1995). Corpus d'extraits musicaux: Indices relatifs à la familiarité, à l'âge d'acquisition et aux évocations verbales. Canadian Journal of Experimental Psychology, 49, 211-239.

Radvansky, G., Fleming, K., \& Simmons, J. (1995). Timbre reliance in nonmusicians' and musicians' memory for melodies. Music Perception, 13, 127-140.

RaJARAM, S., \& RoEDiger, H. L., III (1993). Direct comparison of four implicit memory tests. Journal of Experimental Psychology: Learning, Memory, \& Cognition, 19, 765-776.

ROEDIGER, H. L., III, \& MCDERMOTT, K. (1993). Implicit memory in normal human subjects. In F. Boller \& J. Grafman (Eds.), Handbook of Neuropsychology (Vol. 8, pp. 63-131). Amsterdam: Elsevier.

Roediger, H. L., III, Weldon, M. L., Stadler, M. L., \& Riegler, G. L. (1992). Direct comparison of two implicit memory tests: Word fragment and word stem completion. Journal of Experimental Psychology: Learning, Memory, \& Cognition, 18, 1251-1269.

Russel, P. (1987). Memory for music: A study of musical and listener factors. British Journal of Psychology, 78, 335-347.
SCHACTER, D. L. (1987). Implicit memory: History and current status. Journal of Experimental Psychology: Learning, Memory, \& Cognition, 13, 501-518.

SCHACTER, D. L., Bowers, J., \& Booker, J. (1989). Intentional awareness and implicit memory: The retrieval intentionality criterion. In S. Lewandowsky, J. Dunn, \& K. Kirsner (Eds.), Implicit memory: Theoretical issues (pp. 47-65). Hillsdale, NJ: Erlbaum.

SCHACTER, D. L., \& CHURCH, B. A. (1992). Auditory priming: Implicit and explicit memory for words and voices. Journal of Experimental Psychology: Learning, Memory, \& Cognition, 18, 915-930.

SCHACTER, D. L., \& CHURCH, B. [A.] (1995). Implicit memory in amnesic patients: When is auditory priming spared? Journal of the International Neuropsychological Society, 1, 434-442.

SchaCter, D. L., ChURCh, B. [A.], \& Bolton, E. (1995). Implicit memory in amnesic patients: Impairment of voice-specific priming. Psychological Science, 6, 20-25.

Schacter, D. L., Church, B. A., \& Osowiecki, D. (1994). Auditory priming in elderly adults: Impairment of voice-specific implicit memory. Memory, 2, 295-323.

Schacter, D. L., Church, B. [A.], \& Treadwell, J. (1994). Implicit memory in amnesic patients: Evidence for spared auditory priming. Psychological Science, 5, 20-25.

Schacter, D. L., CoOper, L. A., \& Delaney, S. M. (1990). Implicit memory for unfamiliar objects depends on access to structural descriptions. Journal of Experimental Psychology: General, 119, 5-24.

Schacter, D. L., Cooper, L. A., Delaney, S. M., Peterson, M. A., \& Tharan, M. (1991). Implicit memory for possible and impossible objects: Constraints on the construction of structural descriptions. Journal of Experimental Psychology: Learning, Memory, \& Cognition, 17, 3-19.

Schacter, D. L., Cooper, L. A., \& Teadwell, J. (1993). Preserved priming of novel objects across size transformation in amnesic patients. Psychological Science, 4, 331-335.

Schacter, D. L., \& Tulving, E. (Eds.) (1994). Memory systems. Cambridge, MA: MIT Press, Bradford Books.

Seamon, J. G., Brody, N., \& Kauff, D. M. (1983). Affective discrimination of stimuli that are not recognized: II. Effect of delay between study and test. Bulletin of the Psychonomic Society, 21, 187-189.

Seamon, J. G., Ganor-Stern, D., Crowley, M. J., Wilson, S. M., WEBER, W. J., O'RourKe, C. M., \& MAHONEY, J. K. (1997). A mere exposure effect for transformed three-dimensional objects: Effects of reflection, size, or color changes on affect and recognition. Memory \& Cognition, 25, 367-374

Seamon, J. G., Williams, P. C., Crowley, M. J., Kim, I. J., Langer, S., Orne, P., \& Wishengrad, D. (1995). The mere exposure effect is based on implicit memory: Effects of stimulus type, encoding conditions, and number of exposures on recognition and affect judgments. Journal of Experimental Psychology: Learning, Memory, \& Cognition, 21, 711-721.

Smith, J. D., \& Melara, R. J. (1990). Aesthetic preference and syntactic prototypicality in music: 'Tis the gift to be simple. Cognition, 34, 279-298.

Snodgrass, J. G., Hishman, E., \& Fan, J. (1996). The sensory match effect in recognition memory: Perceptual fluency or episodic trace? Memory \& Cognition, 24, 367-383.

SQuIRE, L. (1992). Memory and the hippocampus: A synthesis from findings with rats, monkeys, and humans. Psychological Review, 99 , 195-231.

Squire, L. , Shimamura, A., \& Graf, P. (1987). Strength and duration of priming effects in normal subjects and amnesic patients. Neuropsychologia, 25, 195-210.

ToBiAs, B., KiHLSTROM, J., \& SCHACTER, D. L. (1992). Emotion and implicit memory. In S. Christanson (Ed.), The handbook of emotion and memory: Research and theory (pp. 67-92). Hillsdale, NJ: Erlbaum.

Tulving, E. (1985). Memory and consciousness. Canadian Psychologist, 26, 1-12.

Tulving, E., \& Schacter, D. L. (1990). Priming and human memory systems. Science, 247, 301-306.

VAn der Linden, M., Lories, G., \& CoRnille, M. (1993). The abstraction of a central tendency in amnesic patients. Cortex, 29, 543-548. 
Verveer, E., Barry, H., \& Bousfield, W. (1933). Change in affectivity with repetition. American Journal of Psychology, 45, 130-134.

WARrington, E. K., \& Weiskrantz, L. (1970). Amnesic syndrome: Consolidation or retrieval? Nature, 228, 628-630.

Washburn, M., Child, M., \& ABel, T. (1927). The effects of immediate repetition on the pleasantness of music. In M. Schoen (Ed.), The effects of music (pp. 199-210). New York: Harcourt, Brace.

WILSON, W. (1979). Feeling more than we can know: Exposure effects without learning. Journal of Personality \& Social Psychology, 37 811-821.

WOLPERT, R. (1990). Recognition of melody, harmonic accompaniment, and instrumentation: Musicians vs. nonmusicians. Music Perception, 8, 95-106.

YONELINAS, A. (1994). Receiver-operating characteristics in recognition memory: Evidence for a dual-process model. Journal of Experimental Psychology: Learning, Memory, \& Cognition, 20, 1341 1354.

ZAJONC, R. (1968). Attitudinal effects of mere exposure. Journal of Personality \& Social Psychology Monographs, 9 (Pt. 2), 1-28.

\section{NOTES}

1. The analyses performed on the $z$ transform scores obtained in recognition led to results that were similar to those obtained on the parameters derived from the signal detection theory. This was also the case of all the other analyses performed on the recognition data in the present study.

2. An empirical ROC curve can be obtained if, in a single session, we can collect data that can be interpreted as multiple (hit, FA) pairs, which is accomplished by asking subjects to rate their experience on an or- dered scale. The data are interpreted as though the subject was maintaining several response criteria simultaneously. Accuracy can be estimated separately for each criterion. If the empirical ROC has a unit slope on $z$-coordinates (so that the variances of the underlying distribution are equal), the sensitivity measure will be the same at all criteria If the slope of the ROC does not equal 1 , accuracy changes along the decision axis. When the unit slope is unwarranted, the index $d_{a}$ is the most adequate (MacMillan \& Creelman, 1991). When the slope is close to unity, $d_{a}$ is identical to the conventional $d^{\prime}$ index.

3. Although these slight variations in familiarity judgments provided in the study phase were not found to affect the subsequent liking and recognition judgments in Experiment 1 when the ratings were re-analyzed according to each subject's own categorization of familiarity, we changed two stimuli so as to make the material as homogeneous as possible across subjects

4. Instrument recognition was, however, quite low, as compared with melody recognition. This may be due to two aspects of the procedure: (1) Measurements were less fine grained on the instrument task, which only required a binary forced-choice response (yes or no), whereas the melody recognition task employed a 10-point scale between the two choices; and (2) instrument recognition was presented as a secondary task, conditional on the correct classification of the melody as being old. Both aspects may have somewhat reduced the sensitivity of the instrument recognition task to reveal the content of the stored representations of the studied events.

5. We thank Caroline Palmer for having brought this possibility to our attention.

(Manuscript received December 23, 1996; revision accepted for publication May 23, 1997.) 